\title{
El palacio de Santa María de Huerta (Soria) y el Legado Documental de la familia Cabré en la Universidad Autónoma de Madrid (UAM)
}

\section{The Santa María de Huerta (Soria) and the Cabré family documented legacy of the Universidad Autónoma de Madrid.}

\author{
Gabriela Polak \\ Universidad Autónoma de Madrid
}

Recibido: 05-06-2013

Aceptado: 20-10-2013

\section{Resumen}

El siguiente trabajo sintetiza el estudio realizado gracias a los documentos pertenecientes al Legado documental de Juan y María Encarnación Cabré donado, en su mayor parte, a la Universidad Autónoma de Madrid (UAM), por la familia Cabré, en el año 2006. Nuestro estudio se centra en el caso del palacio de Santa María de Huerta (Soria). Dicho palacio, propiedad de los marqueses de Cerralbo, desde el 1871 sirvió, no solo como residencia de verano sino, además, lugar desde el cual, a partir de 1908, el marqués de Cerralbo organizó los estudios y las excavaciones arqueológicas en las comarcas próximas al río Alto Jalón. La presencia de muy diversa documentación -fotográfica, correspondencia, notas manuscritas y mecanografiadas, tarjetas postales, pruebas de imprenta, etc.- en dicho Legado se debe a que Juan Cabré Aguiló colaboró con el marqués de Cerralbo en sus trabajos de campo y de gabinete con notable anterioridad a la redacción por parte de Cabré del conocido Catálogo Monumental de la Provincia de Soria. Abarca, pues, entre los años 1908 y 1922.

Palabra clave: Historiografía; Juan Cabré Aguiló; Marqués de Cerralbo; Sta. Ma de Huerta; legados documentales

Summary

The following work synthesizes the study carried out on documents belonging to the Documented Legacy of Juan and María Encarnación Cabré, most of which were donated to the Universidad Autónoma de Madrid (UAM) by the Cabré family in 2006. Our study focuses on the case of the Santa María de Huerta Palace (Soria). As of 1871, this palace, belonging to the Marquises of Cerralbo, was not only a summer residence, but was also, as of 1908, the place from which the Marquis of Cerralbo organized archeological studies and digs in the regions near the Alto Jalón River. The diverse documentation present -photographs, correspondence, hand-written and typed notes, postcards, printing proofs, etc.- - within this Legacy was due to the fact that Juan Cabré Aquiló collaborated with the Marquis of Cerralbo on his field and research work long before Cabré wrote the well-known Monumental Catalogue of the Province of Soria. This encompasses the period between 1908 and 1922.

Key Words: Historiography; Juan Cabré Aguiló; Marquis of Cerralbo; Sta. Ma . de Huerta; Documented legacies.

\section{I.- Génesis del Legado Documental de JUAN y Ma EnCARNaCión Cabré.}

Lo que hoy conocemos como Legado documental de Juan y María Encarnación Cabré reúnen 15.850 documentos resultado de toda una vida dedicada a la Arqueología y a la investigación. Numéricamente, el citado Legado reúne una gran mayoría de documentos pertenecientes a Juan Cabré siendo menor los pertenecientes a su hija María Encarnación quien, desde 1927, participó de manera oficial en las excavaciones junto a su padre en el castro de Las Cogotas (Cardeñosa, Ávila) (Cabré et al., 1932; Baquedano, 1993: 46). Y fue ella también quien, tras la muerte de su 
padre en 1947, se quedó con dicha documentación lo que favoreció su conservación integra hasta nuestros días.

Tras su muerte, en 2005, el Legado documental fue organizado por su hijo Juan Morán con un criterio temático: trabajos de campo, estudios e investigaciones puntuales, documentación y correspondencia oficial, cartas personales, así como un importante bloque de varia para documentos que no cumplían de manera estricta ninguna de las temáticas anteriores. Así, de este modo el Legado quedó ordenado en 248 contenedores de muy distintos formatos: 201 archivadores, 12 portafolios, 30 tubos para planos y 5 ficheros.

Un año después la familia Cabré, consciente del valor de todos aquellos documentos, decidió donarlo a la Universidad Autónoma de Madrid. La elección de esta universidad no fue casual, ya que investigadores de dicha universidad habían trabajado en torno a la figura de Juan Cabré a través de sus propias fotografías y documentos originales existentes en museos y archivos nacionales. Nos referimos, en concreto, a la investigación llevada a cabo desde el 1998 en la UAM y que cristalizaron con la publicación de una trilogía sobre el mundo ibérico: Un homenaje a la memoria (Blánquez y Roldán, 1999a), Las colecciones madrileñas (Blánquez y Roldán, 1999b) y, por último, El litoral mediterráneo (Blánquez y Roldán 2000). Ello, a su vez, favoreció la firma de un proyecto de colaboración en 2001 entre la UAM y el, por entonces, Instituto del Patrimonio Histórico Español (IPHE) del Ministerio de Cultura (hoy Instituto del Patrimonio Cultural de España, IPCE). Aquel proyecto conllevó la digitalización y catalogación de los fondos fotográficos de Juan Cabré donados al citado IPHE por la familia Cabré. De este modo, por primera vez un archivo fotográfico de tal envergadura -con más de 5.500 negativos en placas fotográficas y en nitrato de celulosa-quedó completamente digitalizado en España. Aquel proyecto de colaboración culminó con la realización de una exposición y su correspondiente catálogo dedicado a la vida y obra de Juan Cabré bajo el título El arqueólogo Juan Cabré (1882-1947). La fotografía como técnica documental (Blánquez y Rodríguez, 2004).

Todo este cúmulo de circunstancias favoreció, como decíamos, la donación del Legado documental de Juan y Maria Encarnación Cabré a la UAM. Así, el 15 de junio de 2006, en el despacho del Rector de la Universidad Autónoma, Ángel Gabilondo Pujol, y con la presencia del hijo de Juan Cabré -Enrique Cabré- y de sus nietos -Enrique Cabré Sánchez, Asunción Morán Cabré y Juan Morán Cabré-, de profesores de los departamentos de Prehistoria y Arqueología y de Historia y Teoría del Arte, así como amigos de la familia Cabré se materializó su altruista donación a esta universidad.

\section{II.- El Legado DOCUMENTAL Y LA Universidad Autónoma de MADRID}

El Legado, por disposición del Rectorado, quedó depositado en una Sala de Investigación, específicamente dedicada a guardar y estudiar legados documentales procedentes de arqueólogos españoles que, desde hace hoy ya 13 años, se había creado para tal fin en la Facultad de Filosofía y Letras. Se comenzó, así, una laboriosa tarea de inventario y recatalogación -ahora más detallada- que favoreció el que, en el año 2009, se iniciara un nuevo proyecto de investigación, esta vez de I+D+i, que en junio de 2012 ha terminado en su primera fase de inventariado, catalogación y parcial digitalización: El Legado documental de Juan y María Encarnación Cabré (HAR200806096/HIST).

Por un lado, para su correcta conservación adoptamos medidas encaminadas a un adecuado archivo de la documentación en papel mediante fundas individuales de polipropileno. Paralelamente, los documentos fotográficos (positivos y negativos) se utilizaron fundas Mylar, dado que éstas, como es sabido, protegen de la luz ultravioleta. Por otro lado, se adoptaron distintos tipos de archivadores en función de la tipología de los documentos. Por ejemplo, en el caso de los documentos en papel archivadores estándar, los populares "AZ", mientras que para la documentación fotográfica y dibujos (menores o igual a DIN A2) archivadores especiales de cartón neutro; es decir, sin ácido. A su vez, a cada documento se le asignó un número de inventario individualizado que, al haberse introducido en una Bases de Datos, permitió respetar la ordenación temática original acometida, en su día, por Juan Morán.

Una vez realizados aquellos imprescindibles previos trabajos procedimos a su catalogación e informatización. Para ello creamos una Base de Datos, especialmente diseñada para tal fin, que 
recogía las muy diferentes características de cada uno de los documentos, dada su variabilidad formal: dibujos, fotos, diarios de excavación... Nos referimos a datos como su ubicación original según la organización establecida por Juan Morán; la ubicación actual según los nuevos archivadores de la UAM; y, sobre todo, aquellos datos referentes a los propios documentos: $\mathrm{n}^{\circ} \mathrm{de}$ inventario, temática, autor, título, formato o medidas, además del estado de conservación.

\section{III.- Documentos sobre el Palacio de Santa María de Huerta (Soria) en el Legado}

Entre los documentos del Legado hay parte significativa que hace alusión al palacio de Santa María de Huerta (Soria) propiedad, de como es sabido, de los marqueses de Cerralbo. Su existencia se debe a la colaboración de Juan Cabré con el marqués entre los años 1908 y 1922. Dichos documentos nos permiten conocer el palacio, de cómo era, pero, además, también nos permite conocer las actividades y el día día llevadas a cabo por el citado marqués y por su familia tanto en el palacio como en sus proximidades.

Del conjunto documental aquellos más significativos son las fotografías, en su gran mayoría realizadas por él propio Juan Cabré, aunque también se guardan fotografías realizadas por otras personas o aquellas otras procedentes de estudios fotográficos, como los de casa Hauser y Menet situado en la madrileña calle Ballesta $\mathrm{n}^{\circ} 3$, uno de los primeros establecimientos fotográficos en Madrid (González, 2006: 205). Todo el conjunto de las fotografías lo podríamos dividir en dos grandes bloques. El primero, que hace alusión al propio palacio -su arquitectura, las estancias, la decoración o su entorno-, que además, muchas veces sirvió de fondo para las tomas donde aparecían los marqueses, sus familiares o sus invitados. $\mathrm{Y}$ el segundo bloque, de aquellas fotografías directamente vinculados con sus trabajos de campo, verdaderas instantáneas de los yacimientos y de los materiales arqueológicos.

La correspondencia también es otro de los documentos significativos dentro de este grupo documental. Sobre todo destacan, como es obvio, las cartas dirigidas a Juan Cabré tanto del marqués de Cerralbo y como de uno de sus colaboradores: el párroco Justo Juberías Pérez. No obstante, hay correspondencia dirigida al propio mar- qués de Cerralbo procedentes de diversos investigadores tanto españoles como extranjeros. Valgan como ejemplos las de abate Henri Breuil, Edouard Harlé, Émile Cartailhac, Joseph Déchelette, entre otros. La correspondencia constituye, pues una documentación muy valiosa ya que aporta información sobre los trabajos arqueológicos realizados, su transcurso y descubrimientos, visitas, etc.

Las notas manuscritas y mecanografiadas corresponden a documentos que hacen alusión al palacio. Uno de los claros ejemplos es la descripción del palacio realizada por Juan Cabré para el Catálogo Monumental de la Provincia de Soria. En él Juan Cabré dedicó unas páginas para describirlo, así como sus colecciones más destacadas (Cabré, 1917: 65). Queríamos resaltar que nos encontramos ante la primera descripción conocida del palacio. Existe, además documentación relacionada con las excavaciones arqueológicas realizadas en las comarcas próximas a Santa María de Huerta, así los inventarios de los materiales arqueológicos, los cuadernos -a modo de diarios de excavación- y hojas de campo.

Por su parte, las tarjetas postales escritas (González, 2006: 225) están dirigidas en su totalidad a Juan Cabré. También se conservan aquellas que contienen imagen de Santa María de Huerta, sobre todo de su paisaje y del famoso monasterio cisterciense, objeto de estudio por parte de marqués y tema de su conferencia del ingreso a la Real Academia de la Historia en el 1908 (Cerralbo, 1908).

Respecto a las pruebas de imprenta, éstas hacen referencia a bocetos de los artículos de marqués de Cerralbo, como es el caso de la Conferencia pronunciada por él en el Congreso Internacional celebrado en Ginebra en el 1912, para la cual Juan Cabré fue uno de las personas encargadas de la parte gráfica para dicho artículo (Cerralbo, 1912a); o las pruebas de imprenta de las imágenes fotográficas que Cabré usaba para la realización de las fichas, las que él solía llamar "papeletas fotográficas", sobre todo de materiales arqueológicos en los que apuntaba la procedencia y las características tipológicas del objeto.

Todas estas cinco tipologías de documentos nos permiten obtener hoy una información distinta y ampliada. Sus fotografías nos permiten una lectura psicológica; la correspondencia la intra- 
historia; las notas manuscritas y mecanografiadas la relectura de trabajos ya publicados y las tarjetas postales y pruebas de imprenta un claro carácter complementario al todo anterior.

\section{IV.- El palacio de Santa María de Huerta (Soria)}

Como es sabido, Santa María de Huerta es una fundación monacal cisterciense, de ahí su nombre ya que Santa María fue una de las protectoras de la congregación. Las primeras noticias de este monacato, que se tienen, son del siglo XII, cuando los monjes decidieron establecerse allí aprovechando las condiciones idóneas para el cultivo de las tierras -su fertilidad y su proximidad al rio-. A partir de entonces el pueblo empezó a funcionar y crecer favorecido por la llegada de gente que se estableció alrededor del monasterio (García, 1892: 21 y ss.). Con la desamortización de Mendizábal, en el 1833, una vez confiscados todos los bienes a los monjes, éstos abandonaron el pueblo y hasta el 1930 no regresan de nuevo a Santa María de Huerta. Mientras tanto, tanto las propiedades como los terrenos pertenecientes a la congregación salieron a subasta y gran parte de ellos fueron adquiridos por la que sería la futura mujer de marqués de Cerralbo, Inocencia Valle Serrano y Cerver, en el 1846. Tras su casamiento, en el 1971, decidieron establecer allí su residencia de verano. Posteriormente todas aquellas propiedades, tras la muerte de la marquesa, en 1896, el marqués de Cerralbo heredó para su usufructo en vida. En el
1922, por cláusula testamentaría, las propiedades pasaron a Amelia del Valles y Serrano, hijastra del marqués (Granados, 2009: 92 y 95).

El palacio estaba situado enfrente del monasterio y, además, daba a las vías del ferrocarril -Madrid Zaragoza-, y mientras que en su parte posterior colindaba con el rio Alto Jalón (fig.1) (Masferrer, 1916: 520). Aunque aprovechaba antiguas posesiones monacales se trataba de construcción moderna, ya que los marqueses decidieron realizar algunas reformas para adecuarlo como vivienda y dotarlo de un aspecto moderno, acorde al estilo arquitectónico vigente de la época. Durante aquel periodo empezaban a verse los primeros ensayos del llamado "historicismo arquitectónico" basado en la combinación de diferentes estilos, como el neogótico, en sus torrecillas y sus pináculos, o el neorrománico y el uso de diferentes elementos, a modo de decoración: torreones, almenas y miradores, pórticos, balcones, balaustradas, arquerías o la combinación entre revoco y obra vista (Alonso, 2005: 179 y ss.).

Tenía una planta en forma de "L" articulada en cuatro cuerpos de plantas rectangulares a las que se adosaban construcciones de menor tamaño como las torres y esquineras que muchas veces servían de distribuidores y, sobre todo para comunicar los distintos cuerpos entre sí.

Sabemos que el palacio contaba con dos alturas y que, en principio, la primera planta estaba destinada para la vida en los meses de verano mientras que la segunda era para el invierno. No

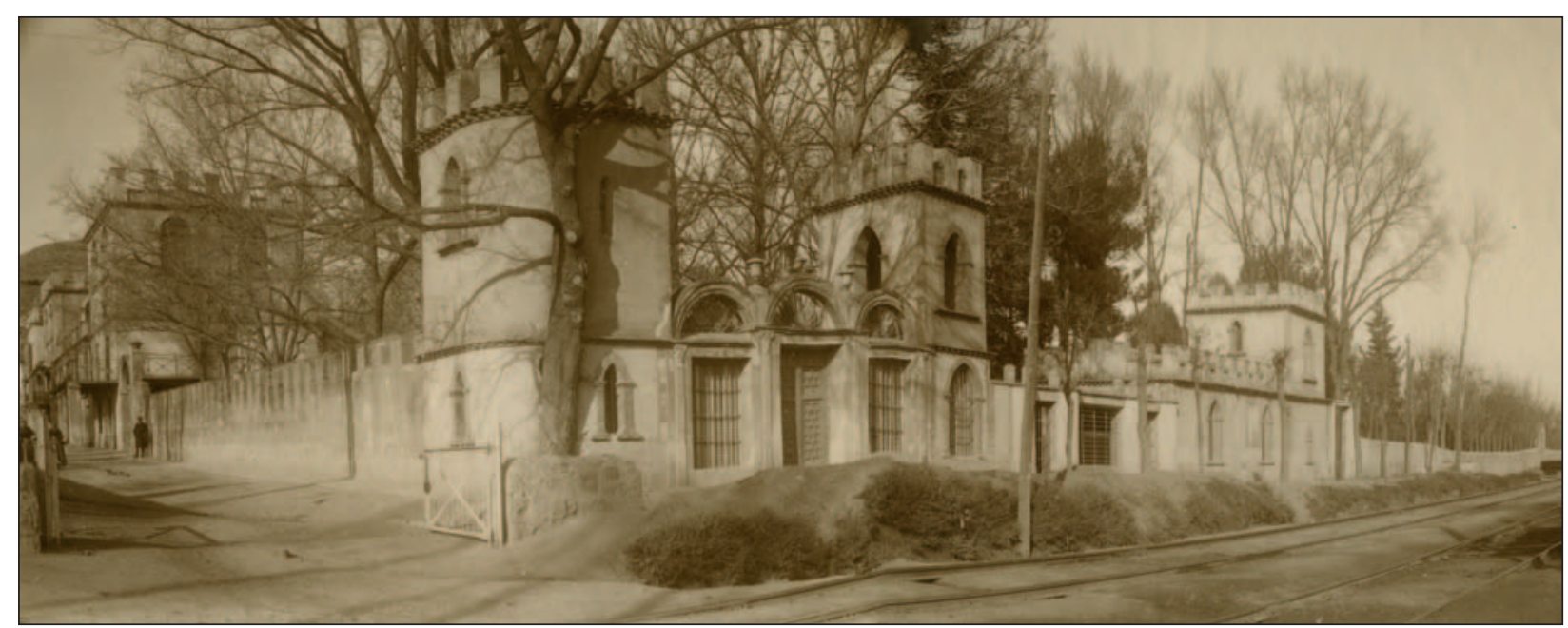

Figura 1. Vista del palacio desde la estación de ferrocarril "Madrid-Zaragoza". Al fondo, a la izquierda, Enrique Aguilera y Gamboa, el XVII ${ }^{\circ}$ marqués de Cerralbo. Legado familia Cabré, UAM (nº inv. 12623 y 12626). 
obstante, muchas de ellas, según relato del propio marqués, con el tiempo y por falta de espacio se convirtieron en "almacenes" temporales para los materiales procedentes de sus excavaciones. Es más, llegó a convertir estancias dedicadas a la cría de caballos también para guardar materiales. Así, en una carta dirigida al Presidente del Patronato Antonio Becerril en 20 de febrero de 1929 Juan Cabré comentaba (...) Lo mas interesante que queda en los Pabellones del patio de Caballerizas, es el lote de Colmillos de Torralba, uno de ellos quizás único en el mundo y por lo tanto de importancia extraordinaria. (...) (Legado familia Cabré, UAM. No inv. 09823).

Respecto a la decoración de las fachadas ésta era muy sobria. Tan sólo destacaba en su fachada principal el escudo de armas flanqueado por dos leones rampantes y coronados con la corona de marquesado. Su parte derecha correspondía al linaje familiar del marqués de Cerralbo y la parte izquierda al linaje de la familiar de su mujer, Inocencia del Valley Cerver (fig.2) (Vaquero, 2010: 60).

El palacio estaba rodeado de una tapia en todo su perímetro no edificado y para acceder a su interior había que pasar por una ancha avenida que permitía llegar en carruaje hasta el acceso principal al palacio. Dicha avenida, a lo largo de su recorrido, estaba decorada por fuentes ornamentales y plantas aromáticas, además de setos y árboles (fig.3). A partir de aquella se accedía, además, a otros espacios, ajardinados, ya que el palacio se encontraba rodeado por diferentes tipos de jardines. Por un lado, contaba con un jardín romántico -al estilo inglés- que se caracterizaba por sus caminos tortuosos, amplias praderas, vegetación de setos y árboles, así como por plantas aromáticas, todos ellas colocadas al azar y de crecimiento libre que otorgaban un aspecto silvestre. Por otro lado se construyeron lagos artificiales, con puentes, que dotaron a los jardines de una incuestionable imagen de carácter exótico. A partir del siglo XVIII la admiración por los tiempos pasados, como el mundo clásico o medieval, favorecieron la introducción en aquellos espacios ajardinados de elementos del pasado; tanto originales como recreacio- nes de falsas ruinas, templos clásicos o elementos orientales (Fariello, 2004: 214). Con respecto a sus jardines de estilo francés se caracterizaba, como es lógico, por la organización simétrica de todos sus elementos, así como por su distribución alrededor a un punto central o favorecer una visión total del mismo cuando se contemplaban desde el palacio o las terrazas del mismo (Fariello, 2004: 125). De hecho desde el balcón dispuesto en su fachada principal del palacio se podía disfrutar de todas aquellas vistas ordenadas por la citada avenida principal. Por último y aunque dentro del Legado no se conservan fotos sabemos que el palacio también contaba con un huerto y una extensa pradera situadas en la parte trasera del mismo (Masferrer, 1916: 520).

La avenida principal y los distintos espacios ajardinados se adornaba con esculturas, bustos, elementos arquitectónicos y macetas cerámicas. Algunas de aquellas procedían de las compras que marqués realizaba, tanto en España como de

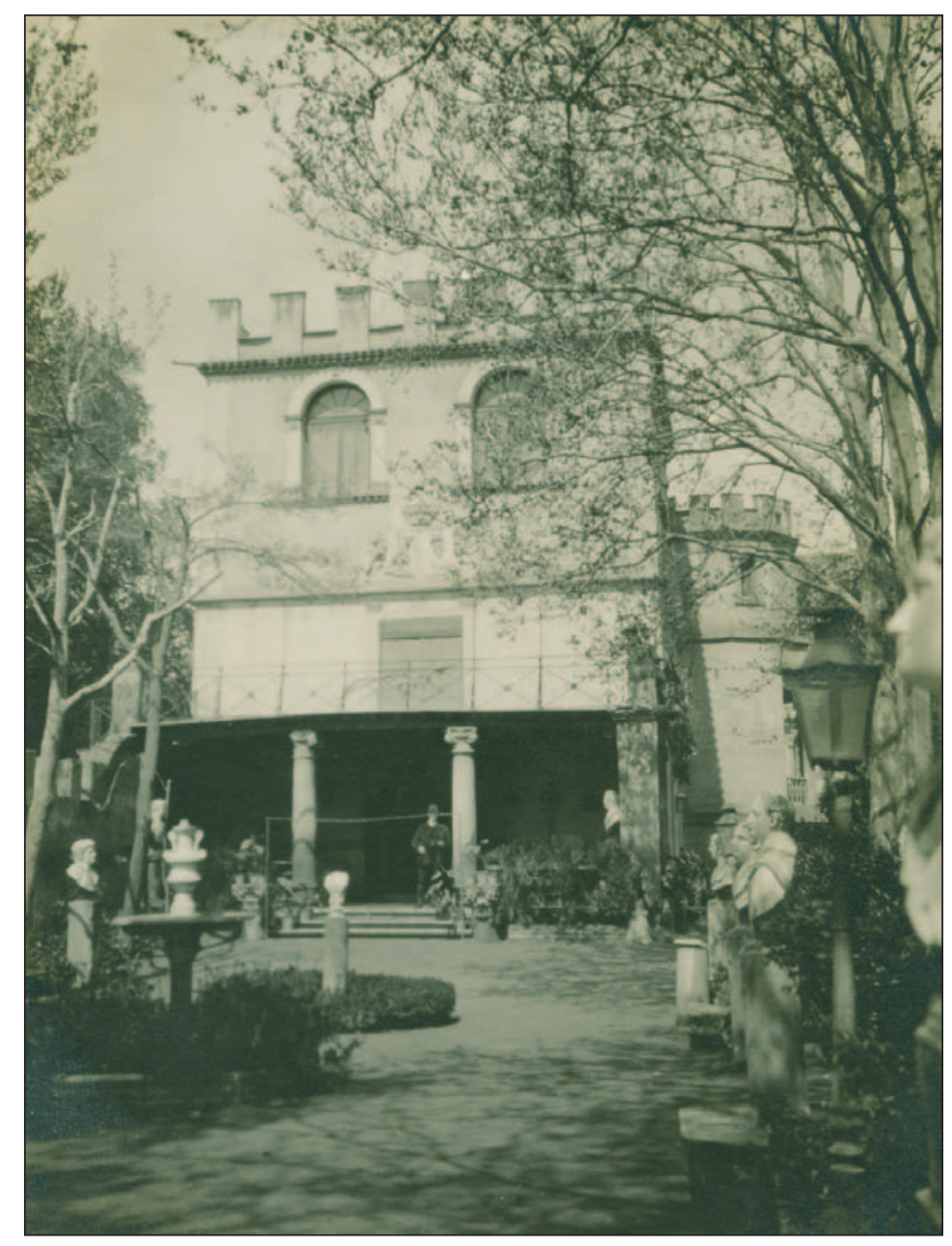

Figura 2. Fachada principal del palacio de Santa María de Huerta. Legado familia Cabré, UAM (nº inv. 12638). 


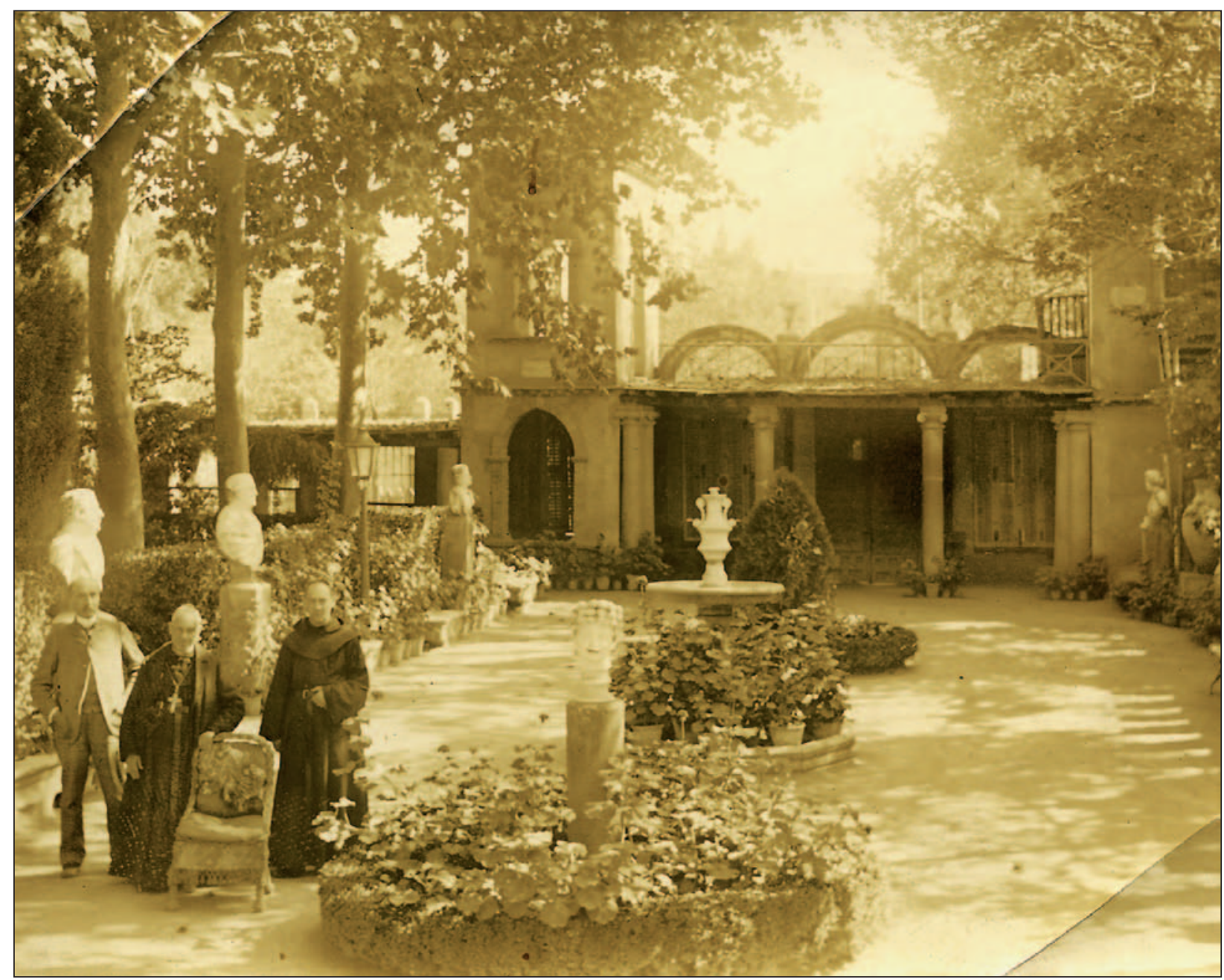

Figura 3 El marqués de Cerralbo y el obispo de Sigüenza en la avenida principal del palacio de Santa María de Huerta. Legado familia Cabré, UAM (nº inv. 02548).

subastas europeas que frecuentaba habitualmente. Respecto a las primeras por ejemplo en el año 1884 en la subasta adquiere numerosas piezas artísticas de marqués de Salamanca y, con respecto a las segundas sobre todo las organizadas en Italia y Francia (Granados, 2009: 99). No obstante algunos otras procedían de sus excavaciones, como era el caso de elementos arquitectónicos procedentes del yacimiento de Arcobriga (Monreal de Ariza, Zaragoza). Posteriormente todos aquellos elementos fueron trasladados al Museo Cerralbo y hoy, la mayoría de ellos, adornan su actual jardín (Vaquero et al., 2010: 32 y 35).

Respecto al interior del palacio, tanto su decoración como la distribución de sus estancias, tenemos poca información. Incluso dentro de los documentos de Legado solo se conservan dos fotografías. De hecho, el propio Juan Cabré, en la parte referida al Palacio en el Catálogo
Monumental hizo una descripción de su interior muy por encima; tan sólo destacó sus riquezas decorativas como cuadros de los principales pintores europeos de la escuela italiana, caso de Verones hijo o de la escuela española caso de José Camarón o José Soriano Fort; también cita sus tapices y muebles significativos (Cabré, 1917: 65).

Desde principio el palacio estuvo destinado a ser residencia de verano de los marqueses y, consecuencia de ello se convirtió en vista obligatoria para la alta burguesía y nobleza española de aquellos tiempos. Por sus estancias pasaron, entre otros, el duques de Gor y de Ciudad Real; los condes de Benalúa; el barrón de Yecla; el obispo de Sigüenza como el propio príncipe de Mónaco, que visitó el palacio en el año 1912 (Kasabal, 1891; Legado familia Cabré, UAM. $\mathrm{N}^{\mathrm{o}}$ inv. 04823). 
Durante las largas estancias de verano los márquese proporcionaban a sus invitados multitud de diversiones, desde la caza -aprovechando los extensos bosques y campos del entorno del Santa María de Huerta- hasta largos paseos a caballo, ya que marqués contaba con una importante yeguada, una de las mejores de España. De hecho llegó a participar en concursos de caballos y de carruajes con la "yeguada de Santa María de Huerta" e, incluso llegó a obtener el primer premio en las exposiciones de Madrid y Barcelona en el 1902 por el cruce de pura raza inglesa e hispana (Navascués et al., 1996: 24).

También organizó veladas literarias y artísticas, ya que tanto marqués como su hijastro -Antonio $\mathrm{M}^{\mathrm{a}}$. del Valle y Serrano- eran conocidos por su apego por las Letras; de hecho ambos fueron autores de poemas y novelas románticas (Navascués et al., 1996: 13 y ss.). El marqués era conocido, sobre todo por los poemas, entre otros de temas históricos como: ¡Ruinas! o El Arco Romano de Medinaceli, este último recogido por Juan Valera en su Antología de poetas castellanos. A su vez, de su hijastro podíamos destacar su novela romántica Viajes, hazañas y aventuras de un héroe del siglo XIII, cuyo protagonista era un noble castellano que viaja por países europeos a modo y semejanza de los que él mismo llegó a realizar con toda su familia (Vaquero, 2002: 85 y ss.).

De igual modo, también, eran conocidas sus tertulias sobre arqueología e historia, donde el marqués contaba sus últimos hallazgos y enseñaba las estancias llenas de objetos extraídos de sus excavaciones (Wfyler, 1923: 19). Por último el deporte también formó parte de los entretenimientos ofrecidos por los marqueses: los conocidos partidos de kroquet, deporte este, de moda, por entonces, entre las clases altas y aristocráticas $\mathrm{y}$ venido desde Inglaterra.

Ya en su época el palacio fue el objeto de admiración, tanto por su arquitectura como por sus colecciones, reunidas todas ellas por los marqueses. De hecho las principales revistas del país llegaron hacerse eco de ello, hasta el punto de referirse al palacio como "un verdadero museo" o "un tesoro de riquezas artísticas" (Wfyler, 1923; Masferrer, 1916).

Así, por ejemplo, la revista madrileña $E L E$ GANCIAS dirigida al público femenino de la alta burguesía y la nueva aristocracia de aquella época hacía alusión sobre ello. Era una revista de gran formato, editada sobre un magnífico papel couché, que en sus más de 70 páginas combinaba a la perfección el uso de fotograbados, dibujos y fotografías. Casi en su totalidad estaba dedicada a la moda y a sus complementos, aunque también contaba con una sección dedicada a las casas y palacios de la alta burguesía española y, de hecho, en uno de sus números dedicó varias páginas al palacio de Santa María de Huerta (Wfyler, 1923: 18 y ss.).

También, la revista deportiva STADIUM, cuyos artículos estaban dedicados, en su mayoría, a temas de automóviles, también hacían referencias a todo tipo de deportes y al turismo. Así, en el número 167 del año 1916 recogía un artículo sobre el turismo en las provincias de Guadalajara y Soria y, entre los sitios recomendados, figuraba -de nuevo- el palacio de los marqueses, abierto para las visitas de sus estancias, jardines y las citadas colecciones arqueológicas (Masferrer, 1916).

\section{V. -Enrique Aguilera y Gamboa, XVII ${ }^{\circ}$ Mar- Qués de Cerralbo}

Nació en Madrid el 8 de julio de 1845 y, aunque desde siempre tuvo interés por las antigüedades y el coleccionismo, sus primeros años los dedicó a la política. Durante su carrera de Filosofía, Letras y Derecho en la Universidad Central de Madrid, con tan solo 24 años fundó el Partido de las Juventudes Carlistas y llegó a ser el representante de don Carlos y, posteriormente de don Jaime de Borbón, rama aspirante a la corona (Barril, 2004: 188 y ss.). Una vez retirado -temporalmente- de la política convirtió el coleccionismo en su verdadera pasión. Acudía a casas de subastas, anticuarios y exposiciones en búsqueda de curiosidades, antiguiedades y obras de arte. Hasta tal punto llegó su conocimiento en las mismas y, sobre todo en obras de arte, que llegó a tasar la pinacoteca de su amigo Lázaro Galdiano (Alvar, 2007: 25 y 26).

Por otro lado, su interés por conocer lugares le llevó a realizar numerosos viajes a modo del Gran Tour por países europeos, donde acudía a los museos y las galerías, sin dejar de visitar yacimientos, como durante su viaje por Italia a Pompeya (1874) y de las cuales no solo traía objetos sino también fotografías para su propia colección. Hasta el punto de, por encargo, traer a Juan Catalina García López las fotografías de 
los mosaicos de Santa Sofía de Constantinopla durante su viaje por Turquía en el 1889 (Vaquero, 2002: 14).

Su preocupación por la conservación de los vestigios del pasado le llevó a subvencionar, por ejemplo, la restauración del monasterio cisterciense de Santa María de Huerta; o financiar la segunda campaña de las excavaciones de Antonio Vives y Escudero en el yacimiento campaniforme de Ciempozuelos (Madrid), en el año 1895 (Blasco et al., 1998: 6). Su implicación en la arqueológica, así como su preocupación por la conservación y preservación de los vestigios del pasado (Cerralbo, 1900) le llevó a participar en la redacción de la Ley de Excavaciones y Antigüedades de 7 de julio de 1911, siendo por entonces el vicepresidente de la Junta Superior de Excavaciones y Antiguiedades (Gaceta de Madrid, 1911, 95-96; y Alvar, 2007: 35).

Por sus aportaciones a la arqueología e historia entró a formar parte en las Reales Academias de la Historia, en el 1908; de la Lengua, en el 1913 y en de Bellas Artes de San Fernando, en el 1917. Su discurso de ingreso en la Real Academia de Historia versó sobre El Arzobispo D. Rodrigo Ximénez de Rada y el monasterio de Santa María de Huerta, contestado por el académico y amigo íntimo de su años de la carrera, Juan Catalina García. Con ello se convirtió en el Académico número 1.906 (Cerralbo, 1908).

En el año 1911 obtuvo el Premio Internacional Mortorell por su obra Páginas de Historia Patria por mis excavaciones arqueológicas que constaba de cinco tomos y que recogía, por orden cronológico, las excavaciones por él realizadas entre 1908 y 1911 en las comarcas de Alto Jalón. Desde aquel momento, el marqués se convirtió en el primer español distinguido con este premio que, desde el 1887 y cada cinco años, premiaba la mejor obra de arqueología española y que en las ediciones anteriores había recaído en los arqueólogos como los hermanos Luis y Enrique Siret, Emil Hübner, George Bonsor, Adolf Schulten o Pierre Paris, entre otros (Recio y Casas, 2012: 2 y ss.).

Claro ejemplo de esta trayectoria quedo reflejada en su retrato oficial realizado por uno de sus pintores de cámara José Soriano Fort en el año 1903 (Navascués y Conde de Beroldingen, 1998: 120 y ss.) y que hoy forma parte de la exposición permanente del Museo Cerralbo en la "Galería Primera" (Vaquero, 2010: 158). En dicho cuadro observamos sus dos facetas: la del político/aristócrata y la del coleccionista/investigador (fig.4). En marqués posa en su residencia madrileña de la calle Ventura Rodríguez $\mathrm{n}^{\circ} 2$, hoy museo. Aparece vestido como Senador del Reino -por derecho propio desde 1885- con indumentaria de gala, en la mano derecha lleva el sombrero de plumas y en la mano izquierda el espadín de corte. Prende las condecoraciones que le otorgó Carlos de Borbón, la de Caballero de la Orden del Toisón de Oro y el Collar de la Orden del Espíritu Santo, como recompensa por su servicio y dedicación a la causa carlista; también fue Caballero de la Orden de Malta. A su vez, en la mesa se encuentran objetos de diversa procedencia y cronología que aluden a su inclinación hacia la Historia y Arqueología. Por un lado, una cerámica griega de figuras rojas - un escifo para beber el vino del siglo IV a.C.- y, por otro, partes de armadura, una celda de engole del siglo XVI y que, según la leyenda, perteneció al duque de Saboya y que uso en la batalla de San Quintín (1557) al frente de las tropas españolas de Felipe II, así como unos estribos de samurái procedentes de Japón de los siglos XVII-XVIII. Por último, una selección de libros manuscritos e impresos, reflejo de su biblioteca que contaba con más de 10.000 ejemplares; de hecho estaba considerada como una de las bibliotecas más completas de su época, sobre todo en materia de arqueología y numismática pero que contenía también los libros de viajes, de historia, de geografía, de literatura, de religión, de derecho y de política (Alvar, 2007: 31 y ss.).

\section{V.1.- Las excavaciones arqueológicas proyec- tadas desde el palacio de Santa María de Huerta en las comarcas del Alto Jalón}

Desde su palacio de Santa María de Huerta dirigió y costeó más de un centenar de excavaciones. Como el propio marqués decía yo me lanzo a excavar en mi Patria, y de mi Patria escojo el territorio menos conocido, por ser el central y en él he explorado, de la manera científica que se me alcanza (...) (Navascués et al., 1996: 29). Su objetivo era documentar cualquier vestigio o representación histórica, por eso sus estudios abarcaron desde los yacimientos paleolíticos hasta el siglo XVI como, por ejemplo el estudio del citado monasterio cisterciense de Santa María de Huerta (Soria). 


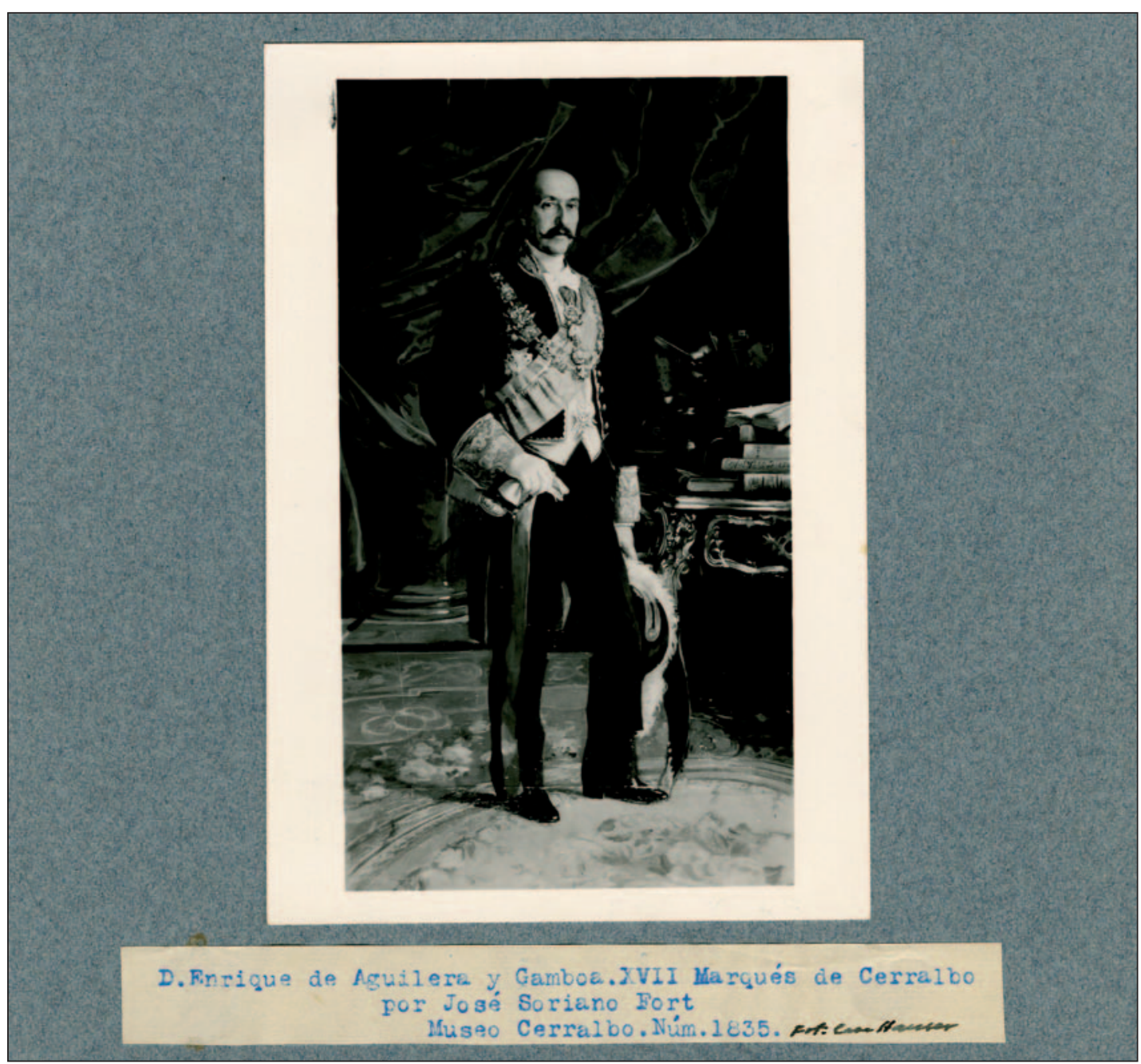

Figura 4 Retrato oficial del XVII ${ }^{\circ}$ marqués de Cerralbo, por su pintor de cámara J. Soriano Fort, en 1903. Legado familia Cabré, UAM (n inv. 09099).

Dentro de esta línea de actuaciones entraban todos los vestigios ubicados a lo largo del Alto Jalón, lo que hoy se corresponde con las provincias de Soria, Zaragoza y, sobre todo, de Guadalajara. Durante aquellos catorce años el marqués realizó alrededor de cien intervenciones arqueológicas (Cabré, 1922b: 315 y ss.; Jiménez Sanz, 2002: 125; Jiménez Sanz y García-Soto, 2008: 522 y ss.). Así, de las 52 las realizó en la provincia de Guadalajara en el Legado tenemos constancia de 31 de ellas; de las de la provincia de Soria (44) tenemos información de 22 intervenciones y, por último de la provincia de Zaragoza tenemos información de las tres excavaciones arqueológicas que realizó. Dentro del Legado contamos, sobre todo con fotografías, quizás ello responde a la afición de Juan Cabré por la fotografía, evidentemente al haber sido colaborador en las excavaciones (fig.5). También se conservan algunos apuntes y cuadernos, a modo de diarios de excavación. En el caso de los dibujos, estos son posteriores, ya que fueron realizadas por María
Encarnación Cabré quien se basó para su realización en las fotografías realizadas por su padre (Baquedano, 2008: 504). Se trata de dibujos de ajuares funerarios, armas y adornos personales, sobre todo de broches de cinturón y fíbulas, y que iban a formar parte de su tesis doctoral sobre Las espadas y puñales del Edad del Hierro de la Península ibérica (Legado familia Cabré, UAM. $\mathrm{N}^{\mathrm{o}}$ inv. 05346).

\section{V.2.- Las necrópolis de la II Edad de Hierro de Guadalajara: un ejemplo de metodología arqueológica}

La metodología aplicada por el marqués y en ello, evidentemente, la presencia de Juan Cabré no fue casual se basaba en una rigurosa documentación de las excavaciones, tanto del propio proceso de la excavacióncomo como del posterior tratamiento de los materiales (Cabré, 1942: 339). Hasta tal punto era importante para marqués la 


\begin{tabular}{|c|c|c|}
\hline \multicolumn{3}{|c|}{ Fotografías en el Legado de las intervenciones arqueológicos realizadas por el XVIIO marqués de Cerralbo } \\
\hline Provincia de Guadalajara & Provincia de Soria & Provincia de Zaragoza \\
\hline $\begin{array}{l}\text { - Alcolea del Pinar } \\
\text { - Necrópolis de Higes } \\
\text { - Necrópolis de Clares } \\
\text { - Necrópolis de Otance } \\
\text { - Necrópolis de Turmiel } \\
\text { - Necrópolis de La Olmeda } \\
\text { - Necrópolis de Carabias } \\
\text { - Necrópolis de Garbajosa } \\
\text { - Acrópolis de Perical } \\
\text { - Cuevas Labradas } \\
\text { - Necrópolis de Valdenovillos } \\
\text { - Cueva de la Merendella } \\
\text { - Necrópolis de Palanzuelos } \\
\text { - Necrópolis de Torresabiñan } \\
\text { - Necrópolis de Luzaga } \\
\text { - Necrópolis Ógmica de Alcolea } \\
\text { Ciruelos } \\
\text { - El Rebollar } \\
\text { - Necrópolis de Sabinar } \\
\text { - Necrópolis de Padilla } \\
\text { - Necrópolis de Renales } \\
\text { - Campamento y necrópolis de } \\
\text { - Nguilar de Anguita } \\
\text { - Necrópolis de El Atence } \\
\text { - Necrópolis de Hijes } \\
\text { - Nuente de la Peña de Los } \\
\text { - Necróno del Morro } \\
\text { - Necrópolis de Drunemeton } \\
\text { - Necrópolis de Palanzuelos }\end{array}$ & $\begin{array}{l}\text { - Torrevicente } \\
\text { - Campamento y necrópolis de } \\
\text { Alpanseque } \\
\text { - Hoya de los Muertos } \\
\text { - Yacimiento paleolítico de Torralba } \\
\text { - Yacimiento paleolítico de Ambrona } \\
\text { - Prado de Jimeu } \\
\text { - Sepulturas de Miño } \\
\text { - Castro ciclópeo de Sta. Mạ. de } \\
\text { Huerta } \\
\text { - Fuentes del Jalón } \\
\text { - Gravera de Molino Benjamin } \\
\text { - Necrópolis del Vado de la Lámpara } \\
\text { - Retortillo } \\
\text { - Necrópolis de Galiana } \\
\text { - Caverna de Mora } \\
\text { - El Atalayo } \\
\text { - Santa María de la Riba de Escalote } \\
\text { - Cueva del Asno (Los Rábanos) } \\
\text { - Cueva de Santa Cristiana } \\
\text { - Arte rupestre de la Cueva Labrada } \\
\text { - Mirabueno }\end{array}$ & $\begin{array}{l}\text { - Polis y necrópolis de Arcóbriga } \\
\text { - Necrópolis de Ógmico o de Granja } \\
\text { de San Pedro } \\
\text { - Piedras de sacrificio de Monreal de } \\
\text { Ariza }\end{array}$ \\
\hline
\end{tabular}

Figura 5. Fotografías en el Legado realizadas por Juan Cabré procedentes de las excavaciones realizadas por marqués de Cerralbo en el de Alto Jalón.

correcta transmisión de los resultados de sus hallazgos que llegó realizar montajes "post-excavación" como en el caso de la necrópolis de Aguilar de Anguita o en Luzaga (Aguilera y Gamboa, 1913: 437). Dichos montajes consistían en emular la realidad al recolocar el ajuar de las tumbas con sus urnas cinerarias, el ajuar y su correspondiente estela (fig.6). De este modo reproducía también las mismas calles en las que fueron encontradas, sólo que ahora dispuestas en superficie. Tal como lo contó en la conferencia pronunciada para la Asociación Española para el Progreso de las Ciencias (Valladolid, 22 de octubre de 1915) donde decía (...) Las fotografías que he presentado precisan una explicación: ya dije que las estelas, aún siendo algunas largas, de tres metros, siempre sin excepción, las hallé enteradas (...). Extrañará, pues, que la fotografía las repre- sente sobre el campo y en correcta formación, todo lo cual se debe a que excavábamos una calle señalando las estelas, volvimos a rellenar aquélla, poniendo encima formadas las piedras, según las encontramos soterradas, y seguimos a otra calle con el mismo procedimiento, logrando a la conclusión presentar las necrópolis tal como estaría en los siglos V, IV o III a.C. (Aguilera y Gamboa, 1916: 15).

Dado que este tipo de necrópolis "alineadas" fueron los primeras de este tipo documentadas en España, unido a los montajes que realizaba marqués, provocó que muchos investigadores consideraron aquellos hallazgos como una invención, incluso llegaron a dudar en su existencia (Almagro Basch, 1942: 104). Había que esperar a posteriores descubrimientos en otros yacimientos 
para reconocer la certeza de las teorías de marqués de Cerralbo como, por ejemplo, en las necrópolis de Alpanseque (Soria)(Cabré, 1942) o de Riba de Saelices (Guadalajara) (Cuadrado, 1968; Cerdeño $e t$ al., 2002).

\section{V.3.-Almacén y gabinete de estudio en el palacio}

Los materiales procedentes de sus excavaciones el marqués los depositaba, de manera provisional, en el palacio hasta el punto que era Imposible describir, en breve espacio, los tesoros arqueológicos que encierra esta mansión señorial, museo de todas las civilizaciones. En sus salones se guardan colecciones prehistóricas desde la piedra tallada a la actual... (Cabré, 1917:56).

Para ello convirtió algunas de las estancias en almacenes y expositores de las piezas y de hecho, en las imágenes fotografías del palacio hoy podemos observar detrás de las piezas las paredes empapeladas de las estancias típicamente habitacionales (Cabré, 1922: 315). Dotó aquellas estancias de estanterías a las que, incluso, para darles mayor valor a las piezas, las decoró con capiteles de pilastra. Tampoco la disposición de los objetos era casual ni fruto del azar. En los estantes superiores colocaba los fragmentos arquitectónicos como elementos que entonces considerados de mayor valor artístico a igual que las esculturas. Más abajo, las cerámicas dispuestas en función de su propio gusto estético y no tanto cronológico, funcional o tipológico. En las siguientes baldas estucos y elementos de menor importancia como ladrillos e incluso fragmentos cerámicos (fig.7). De igual manera, el material también lo disponía en cajas, directamente en el suelo, cuando se trataba de piezas de gran tamaño como, por ejemplo, los procedentes del yacimiento de pleistoceno de Torralba (fig.8).

Cada sala, en principio, estaba dedicada a un yacimiento en concreto y cada conjunto estaba acompañado de una cartela con el nombre del yacimiento o, en el caso de desconocerse, el marqués les asignaba nombres según la tipología del yacimiento añadiendo adjetivos y denominaciones relacionadas con sus características como, por

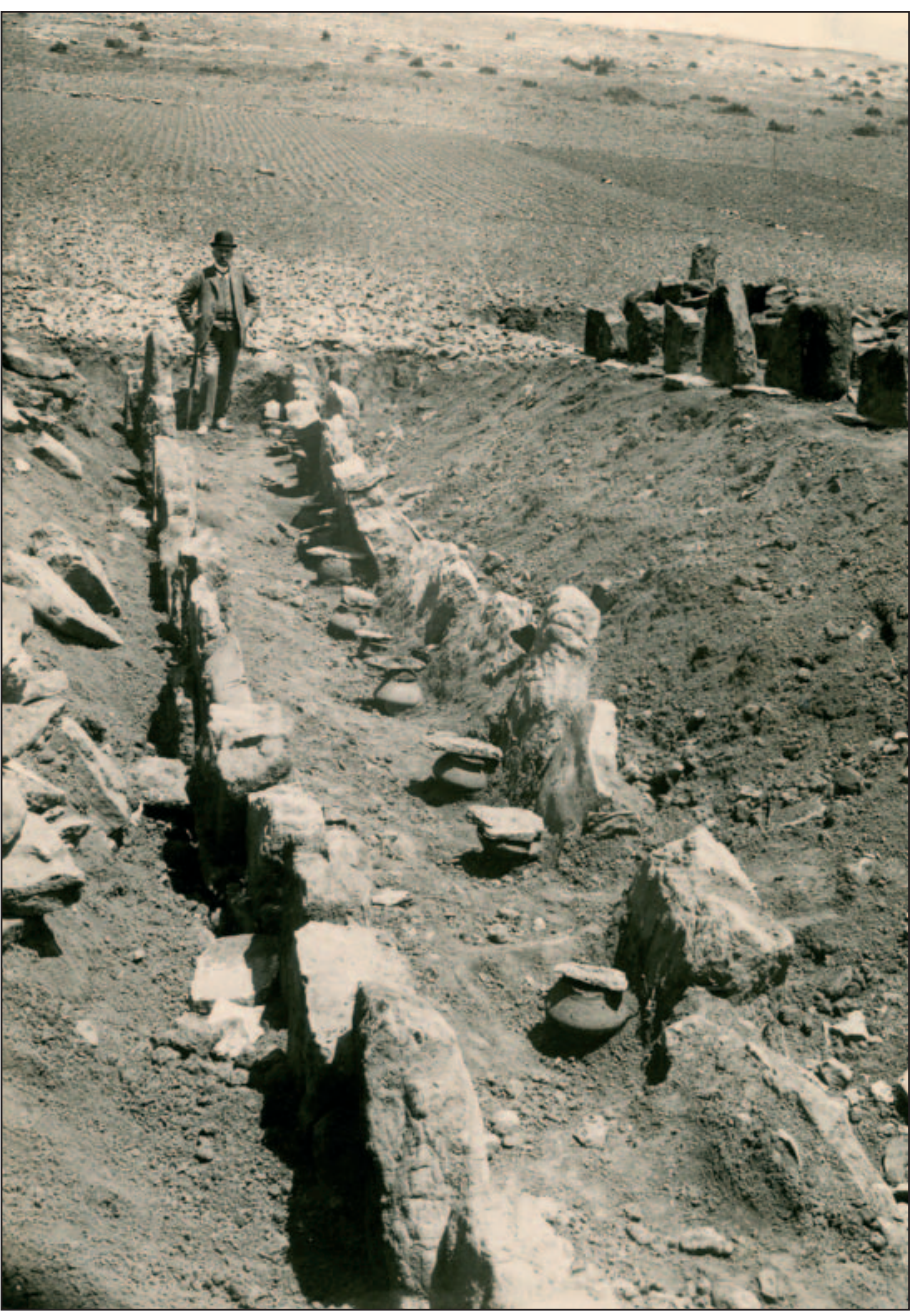

Figura 6. Visita del marqués en la necrópolis de Luzaga (Guadalajara). Legado familia Cabré, UAM (nº inv. 07047).

ejemplo, "asamblea ibérica" o "piedra de los sacrificios" (Jiménez, 2002: 127).

También realizó composiciones y montajes con piezas procedentes de excavaciones, sobre todo aquellos que tenían que ver con el mundo funerario y la simbología de los ajuares. Uno de los ejemplos más característicos era el montaje de fusayolas en forma de espiral (Navascués et al., 1996: 31).

\section{V.4.-Los investigadores en el palacio}

Sus estudios y descubrimientos despertaron el interés de muchos investigadores, tanto extranjeros como españoles. Entre ellos Hugo Obermaier, Adolf Schulten, Joseph Déchelette, Edouard Harlé, Eduardo Hernández-Pacheco o Hermilio Alcalde del Río, que no dudaron en viajar en varias ocasiones a Santa María de Huerta para estudiar las colecciones y conocer 


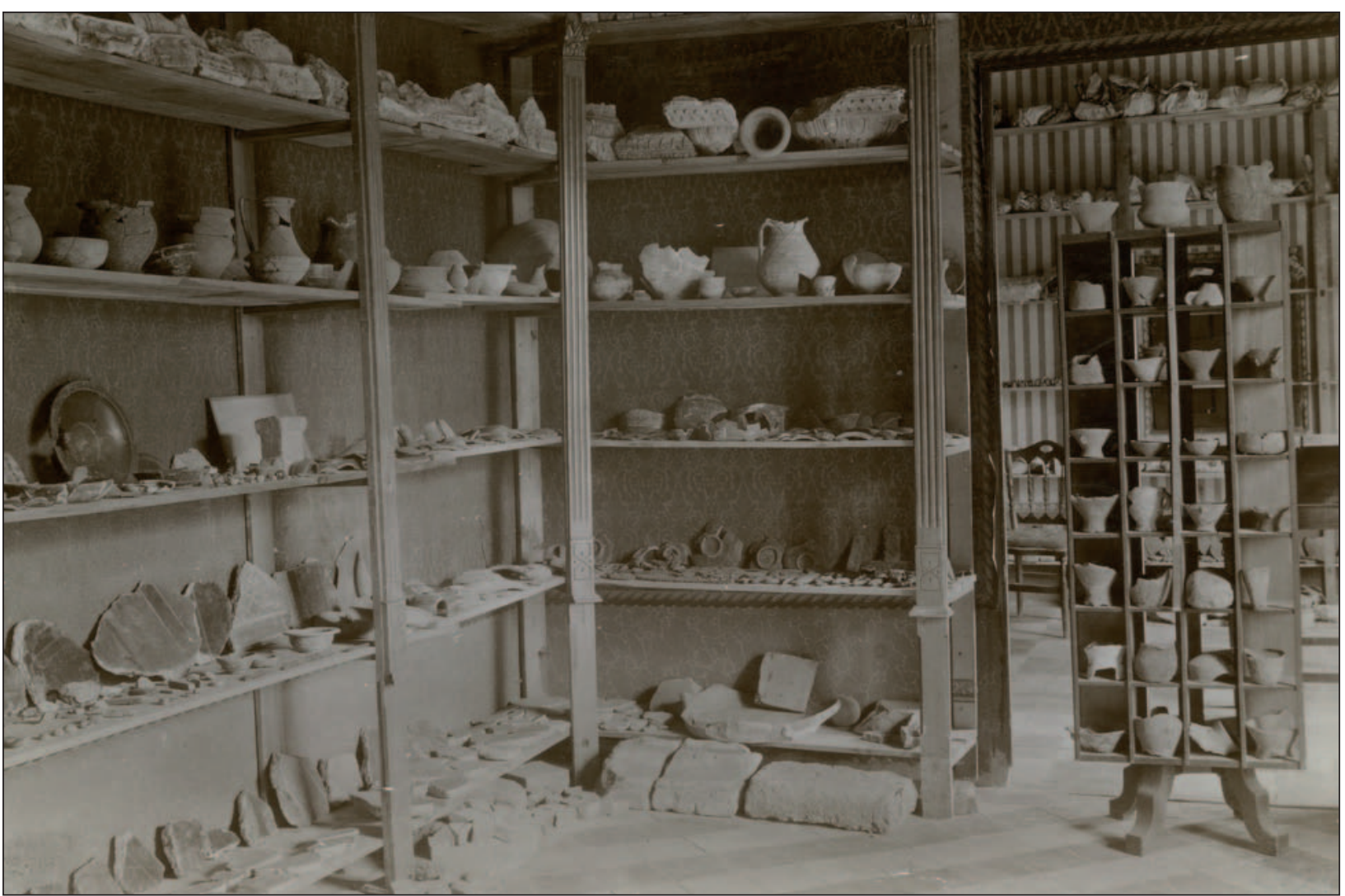

Figura 7. Estancia del palacio dedicada al yacimiento de Arcobriga (Monreal de Ariza, Zaragoza). Legado familia Cabré, UAM ( $\mathrm{n}^{\circ}$ inv. 05440).

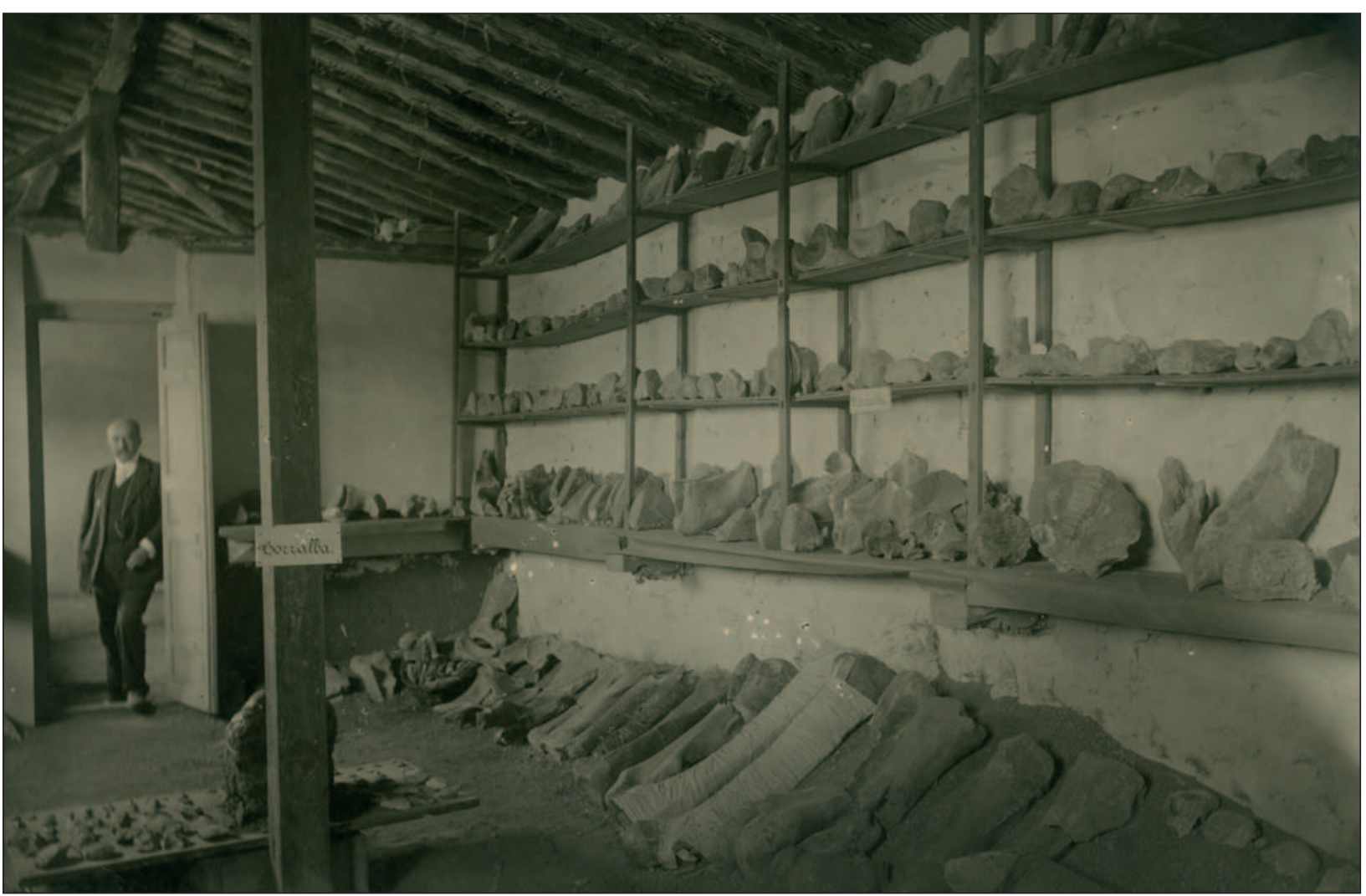

Figura 8. Depósito provisional de materiales arqueológicos procedentes de Torralba (Zaragoza). Al fondo el marqués de Cerralbo. Legado familia Cabré, UAM (nº inv. 11092). 
los yacimientos (fig.9). De aquellas visitas nos informa una carta dirigida a Juan Cabré el 24 septiembre del 1909 (...) Escribí à Mr. Harlé y me ha contestado que vendrá llegando a Santa María de Huerta el día 8 de Octubre y permanecerá aquí una semana, te lo aviso por si tu pasaras por aqui en esos días y te detienes y pudieras conocerle personalmente y si traías algún cajón de huesos de los que hayas hallado y deseases clasificar pudieras aprovechar esa ocasión para que un sabio como Harlé los examinase (...) (Legado familia Cabré, UAM. $\mathrm{N}^{\mathrm{o}}$ inv. 04817).

Una de las razones por el cual los hallazgos del marqués de Cerralbo despertaron el interés entre los investigadores extranjeros fue el hecho de que, aunque desde finales del siglo XIX excavaban en España, el interior de la Península Ibérica donde actuaba el marqués de Cerralbo era un área prácticamente desconocida para aquellos estudiosos (Ayarzagüena y Mora, 2004). De ahí el afán en visitar y comprobar, personalmente, los descubrimientos. La difusión de sus resultados en el Congreso de Ginebra, obtenidos de las excavaciones en Torralba, despertó el interés y la curiosidad por conocer el yacimiento más anti- guo de Europa, y en el que, por primera vez, se encontraron en el mismo yacimiento fósiles de los animales -rinoceronte, caballo, uro, elefanteya extinguidos con útiles líticos realizados por el Hombre. (Cerralbo, 1912b).

Los hallazgos del marqués entre otras cosas permitieron ampliar el conocimiento sobre el paleolítico gracias al estudio del yacimiento de Torralba (Soria) (Santonja y Pérez-González, 2004: 149 y ss.), o sobre las necrópolis celtibéricas hasta entonces apenas conocidos (Cerdeño y García Huerta, 2004: 235 y ss.). Los posteriores estudios permitieron confirmar los rasgos célticos en las culturas meseteñas (Cabré y Morán, 1984: 71), pero incluso establecer periodización y tipologías de escudos, broches de cinturón y espadas.

De igual manera, queríamos destacar como en sus estudios, excavaciones y prospecciones fue habitual la colaboración de diversos especialistas (fig.10). Destacaríamos así, la participación de fotógrafos como Aureliano Pérez Rioja, Francisco de Paula Álvarez-Ossorio, Ricardo Oñate y el propio Juan Cabré (González, 2006:214) y, que el marqués cuidaba e incidía mucho en documentar, de forma exhaustiva, todos los yacimientos y materiales $y$, que posteriormente, utilizaba para

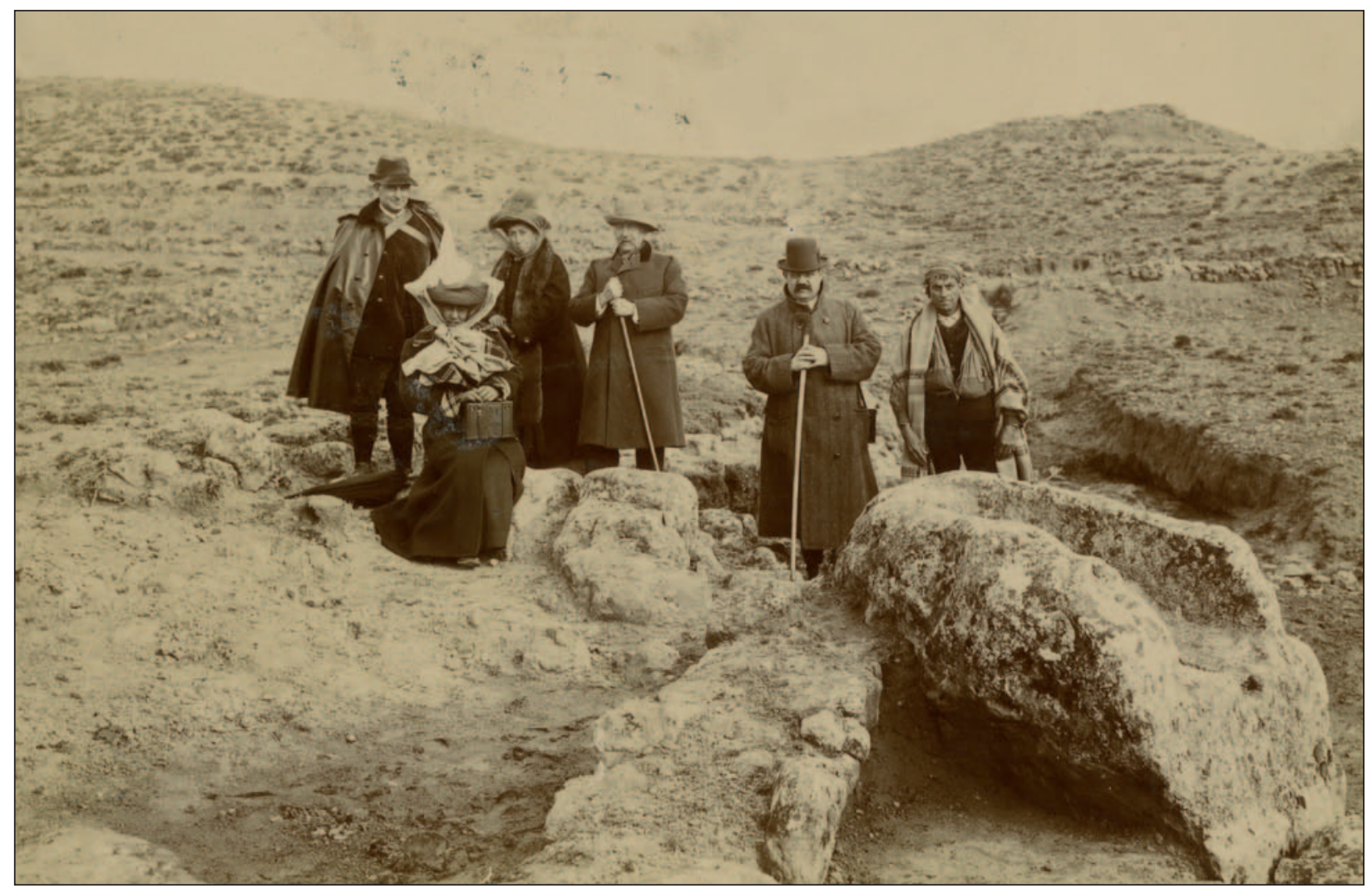

Figura 9. Visita realizada (de izqda.. a dercha.) por J. Déchelette y su mujer, Amelia del Valle y Serrano, marqués de Cerralbo y J. Liñán a la “Asamblea celtibérica”, en 1911. Legado familia Cabré, UAM (nº inv. 14207). 


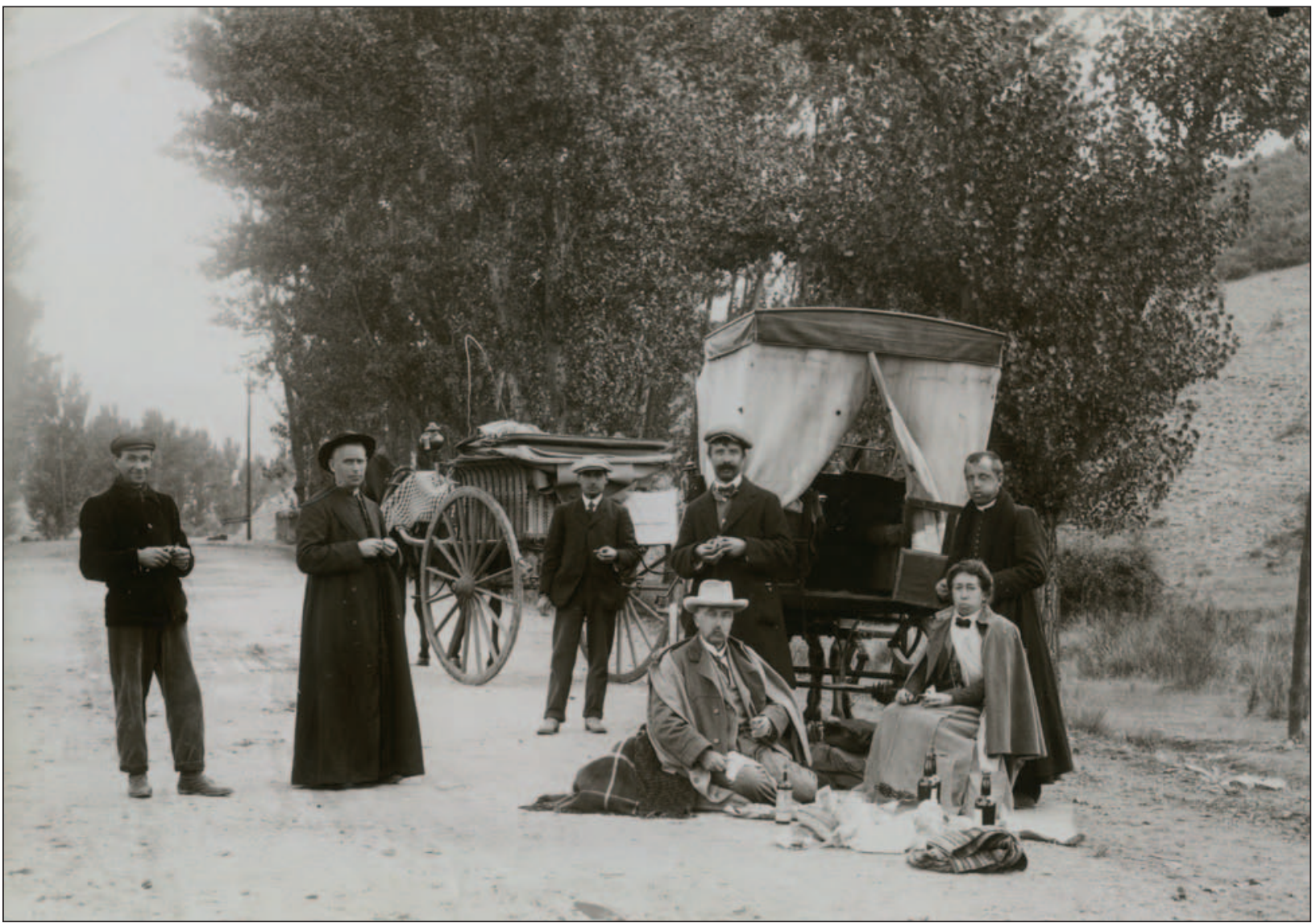

Figura 10. Prospecciones arqueológicas en algún punto de la provincia de Guadalajara.

De izqda. a dercha., marqués de Cerralbo, Amelia del Valle y Serrano, Juan Cabré y Justo Juberías Pérez. Legado familia Cabré, UAM (nº inv. 11617/1).

sus publicaciones y ponencias. Así lo vemos, por ejemplo, en una carta dirigida a Juan Cabré el 12 de enero de 1912 donde decía (...) estoy decidido á publicar mi obra, he comprendido que hay bastantes fotografías que convendría sacar una pruebas mejor, algunos clichés reforzarlós, y sacar otras fotografías de objetos que están englobados con otros, que por la importancia que tienen, y les dieron los arqueólogo extranjeros, interesa fotografiarlos aparte.(...) Por eso pienso llevar á Huerta al fotógrafo Oñate (...) me convendría que fueses á Huerta para hacer algún dibujo de detalle (...) (Legado familia Cabré, UAM. $\mathrm{N}^{\circ}$ inv. 04823).

Otros colaboradores fueron, el geólogo y director de la Escuela de Minas Pedro Palacios y Sáenz o el ingeniero Eugenio Muro. Ambos participaron en las excavaciones de los yacimientos paleolíticos de Torralba y Ambrona, en la provincia de Soria, en donde llegaron a realizar los planos y las secciones estratigráficas. Además, Eugenio Muro se encargó de la realización de la parte gráfica de la obra Páginas de la Historia
Patria por mis excavaciones arqueológicas, mapas y planos realizados, todos ellos, a plumilla y acuarela.

De igual manera, el marqués contó con ayudantes en sus excavaciones que durante su ausencia llevaban la coordinación de los trabajos de campo. Así se desprende de cartas conservadas en el Legado, redactadas por Pascual Melano o de Juan Rincones.

El párroco Justo Juberías Pérez fue también uno de los colaboradores habituales de marqués. Con frecuencia acudía y le acompañaba en sus excavaciones, incluso realizaba prospecciones en solitario para después informarle de los hallazgos y de la importancia de los mismos (Muñoz, 1999: 223).

Por último, también el pueblo llano desempeñó un papel importante en aquellos trabajos de campo, ya que su participación era imprevisible para la realización de las excavaciones pero, no sólo por ello sino también por servir de guías e informadores de hallazgos (Abad, 1922: 53). 


\section{VI.- Juan Cabré Aguiló y su colaboración con el XVII ${ }^{0}$ marqués de Cerralbo}

Cuando Juan Cabré, joven estudiante de Real Academia de Bellas Artes de San Fernando, llegó a Madrid, conoció a marqués de Cerralbo, al parecer bien por recomendación del erudito y coleccionista aragonés Sebastián Montserrat, bien por el historiador, epigrafista y buen amigo del marqués Fidel Fita (Blánquez y González, 2004: 20). Ello le permitió consultar su biblioteca del palacio y, sobre todo, su amplia colección de cuadros y pinturas, ya que su colección de obras de arte no solo abarcaba pintores españoles sino también autores de las principales escuelas europeas: francesa, italiana y flamenca.

Al parecer fue el propio Cabré quien despertó el interés por arqueología en el marqués al enseñarle sus Álbumes con dibujos procedentes de sus excavaciones en los pueblos de Teruel (Morán y Cabré, 1996: 27 y Blánquez et al., 2008), así como sus descubrimientos sobre pinturas rupestres, por entonces desconocidas, tanto en su existencia como en su estilo. Tanto fue así que, ya en el año 1907, la Real Academia de la Historia tenía constancia de los importantes hallazgos realizados por aquel joven Cabré transmitidos éstos a través de Fidel Fita. Todo ello, pensamos, tuvo animar al marqués ya que un año después le invitó a participar en sus excavaciones en Arcobriga (Monreal de Ariza, Zaragoza).

A partir de entonces Cabré compaginó la colaboración con el marqués sobre todo en las temporadas de verano, con sus propios trabajos. Primero cuando colaboraba con el Instituto de Paleontología Humana de Paris y donde, junto con el abate Breuil, llegó a documentar más de 70 estaciones de arte rupestre y a diferenciar entre pinturas levantinas y pinturas esquemáticas (Cabré, 1915), y a partir del 1916, cuando comenzó a dirigir sus propias excavaciones arqueológicas; la primera de ellas en el Collado de los Jardines (Santa Elena,
Jaén); o posteriormente cuando redactaba sucesivos Catálogos Monumentales, primero el de la provincia de Teruel, luego de Soria y, finalmente, de Zaragoza, aunque este último no llegó a entregar el manuscrito.

Un aspecto notable de la colaboración de Cabré con el marqués fue la realización de la mayor parte de las fotografías procedente de sus excavaciones, así como de los materiales arqueológicos aparecidos. Para ello, al parecer, utilizaba la cámara profesional de la marca alemana Carl Zeiss con placas de cristal que, posteriormente, revelaba él mismo, ya que el marqués había mandado a construir un laboratorio fotográfico en el propio palacio. De hecho, tenemos noticias de cómo Cabré, muchas veces, acudía a los yacimientos una vez finalizados los trabajos de campo, para realizar fotografías, tanto del entorno como del conjunto del yacimiento (fig.11) (González, 2004: 50 y ss.).

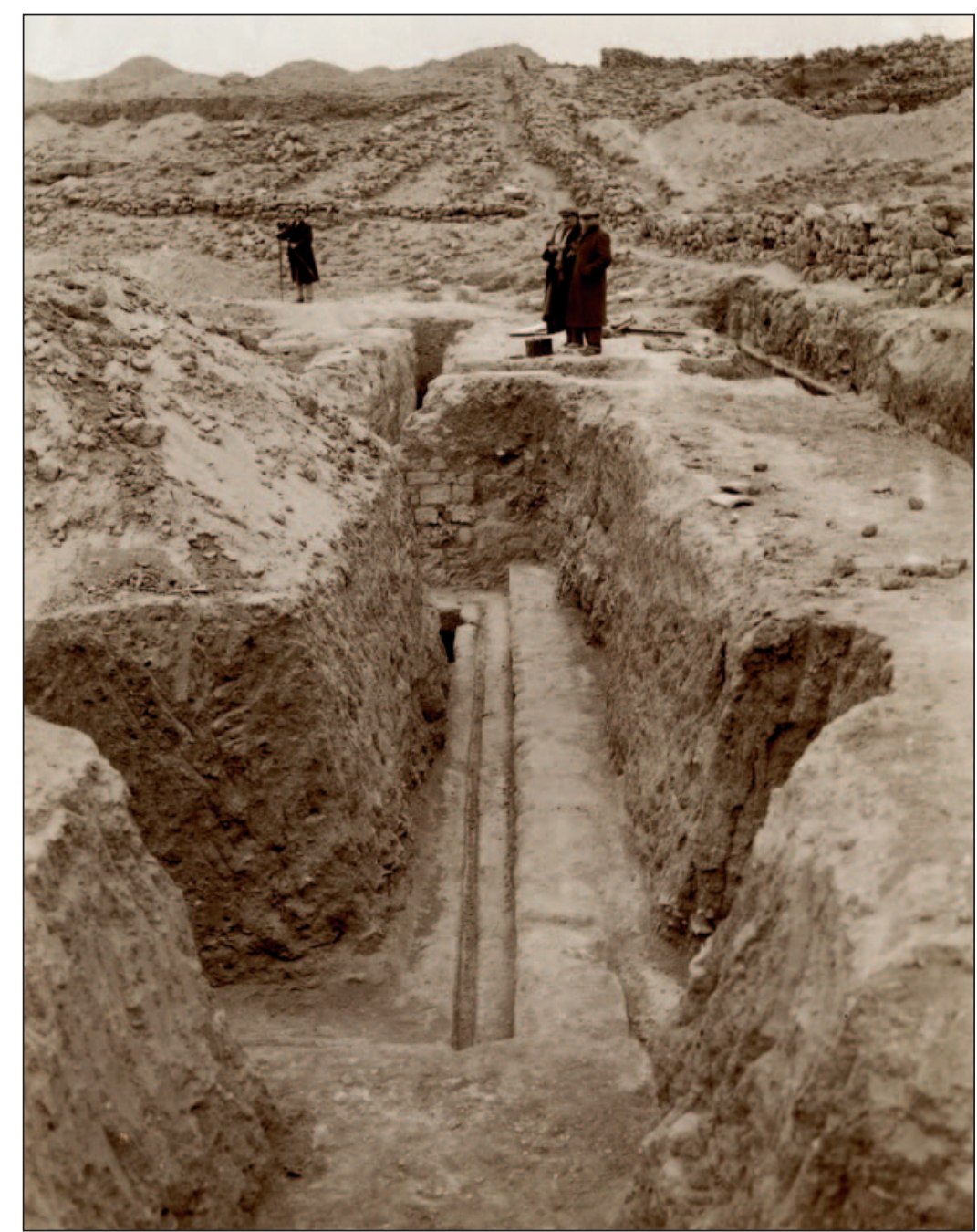

Figura 11. Trabajo de campo de Juan Cabré en Arcobriga (Monreal de Ariza, Zaragoza), hacía 1911. Legado familia Cabré UAM (nº inv. 05469/1). 
También a él se deben la mayoría de los dibujos y gran parte del estudio de los materiales. El procedimiento era el siguiente: primero limpiaba y ordenaba todo el material procedente de las excavaciones respetando su procedencia y tipología; en caso necesario restauraba las piezas, pegaba los fragmentos o realizaba las estructuras de madera para dar más solidez a las piezas óseas (Cabré y Morán, 1993: 114 y ss.) y una vez realizados estos primeros trabajos, procedía a fotografiarlos y dibujarlos (Morán y Cabré, 1996: 30). Con posterioridad enumeraba las placas fotografías e incluso anotaba oportunos pies de fotos donde enunciaba la procedencia de los materiales o ubicación de los yacimientos (González, 2004: 59).

Tras la muerte del marqués en 1922 y por disposición testamentaria Juan Cabré fue nombrado director del Museo Cerralbo (Jiménez y García-Soto, 2004: 94 y 96). Una de las tantas tareas que le fue encomendada fue la realización del inventario de todos los materiales procedentes de aquellas excavaciones, ya que, según voluntad del marqués, todos ellos iban a ser donados al Museo Arqueológico Nacional de Madrid (Cabré, 1922a: 285).

Aquellos materiales estaban depositados en el Museo Cerralbo pero, sobre todo, en el palacio de Santa María de Huerta. Ello obligó a Cabré a desplazarse varias veces para recopilar los datos y a traerse el material, según consta en una de las cartas que Juan Cabré dirigió al Presidente del Patronato del Museo Cerralbo, Antonio Becerril, en 20 de febrero de 1929 (...) en Santa María de Huerta hay todavía muchas cosas, a mi entender lo primero que podía hacerse, si no se quiere perjudicar la marcha de las obras, que allí lo hacen, es trasladar todos los objetos de la necrópolis de Arcóbriga que están en la planta baja de uno de los Pabellones de la Cuadrilla, a Caballerizas. Así mismo todo cuanto existe en el otro Pabellón que forma... con el anterior y lo que hay enfrente de ambos en la estancia llamada la Cuadrilla, junto al cuarto de fotografía. Con esto se dejarían libres estos Pabellones, que es lo único que se puede considerar como del Palacio de Santa María de Huerta. Ello da tiempo si quieren en las vacaciones de Semana Santa (...) (Legado familia Cabré, UAM. $\mathrm{N}^{\circ}$ inv. 09823).

Aquel inventario titulado Relación de los objetos arqueológicos entregados por la Testamentaria del Excmo. Sr. Don Enrique Aguilera y Gamboa, XVII Marqués de Cerralbo, al Museo Arqueológico Nacional de Madrid, según la cláu- sula XXXVII del Testamento otorgado por dicho Excmo. Sr. Con fecha 30 de Junio de 1922, ante el Notario de esta Corte, Don Luis Gallinal y Pedregal (Legado familia Cabré, UAM. No inv. 02047/1-02047/y45) se materializó en un dossier de 168 folios a cuatro caras y en el que se recogía 5.965 números de inventarios que atendían, tanto a piezas individuales como pequeños conjuntos. Cada una de las piezas contaba con una descripción: nombre del objeto, su procedencia, clasificación tipológica, material, medidas y su estado de conservación (fig.12). Un trabajo que le llevó cuatro años. Sin embargo, la primera donación al Museo Arqueológico Nacional está fechada en 1926 pero materializar habría que esperar a 1940 para la última. Aquella labor de cuatro años podía explicarse por una parte, gracias a una carta dirigida a la marquesa de Villa Huerta en 1926 donde puede leerse (...) labor esta que por sí sóla invierte mucho tiempo, por el delicado del asunto, por lo numerosísima que es la colección, porqué no había ni un solo objeto de ella inventariado y sobre todo, porque como estaban muchos objetos de algunos sepulcros revueltos con otros y para desacer muchos de estos enredos se tenía que acudir a las fotografías, que sólo una persona conocedora del asunto como yo podía resolver el problema (Legado familia Cabré, UAM. $\mathrm{N}^{\circ}$ inv. 09822) y por otro, al par con la dirección del Museo Cerralbo, Cabré compaginaba este con sus habituales campañas de excavaciones en la ciudad ibero romana de Cabezo de Alcalá (Azaila, Zaragoza), iniciadas en 1919. En el reconocimiento de todas aquellas aportaciones tanto en este yacimiento como otros importantes descubrimientos de los años anteriores le brindo su ingreso en la Real Academia de Bellas Artes de San Luis de Zaragoza en el 1922. Además desde hacía varios años colaboraba en la sección de Historia del Centro de Estudios Históricos, junto a Manuel GómezMoreno, continuando sus estudios sobre cultura ibérica que vio su recompensa con la publicación, ya en los años cuarenta, de Corpus Vasorum Hispanorum dedicado a la cerámica de Azaila (Cabré, 1944); y por último, también trabajaba como colector interino en el Museo Antropológico Nacional desde el 1920.

\section{Algunas consideraciones finales}

Creemos, pues, evidente que los legados documentales y, evidentemente, de la familia Cabré de manera muy destacada, aporta importante infor- 


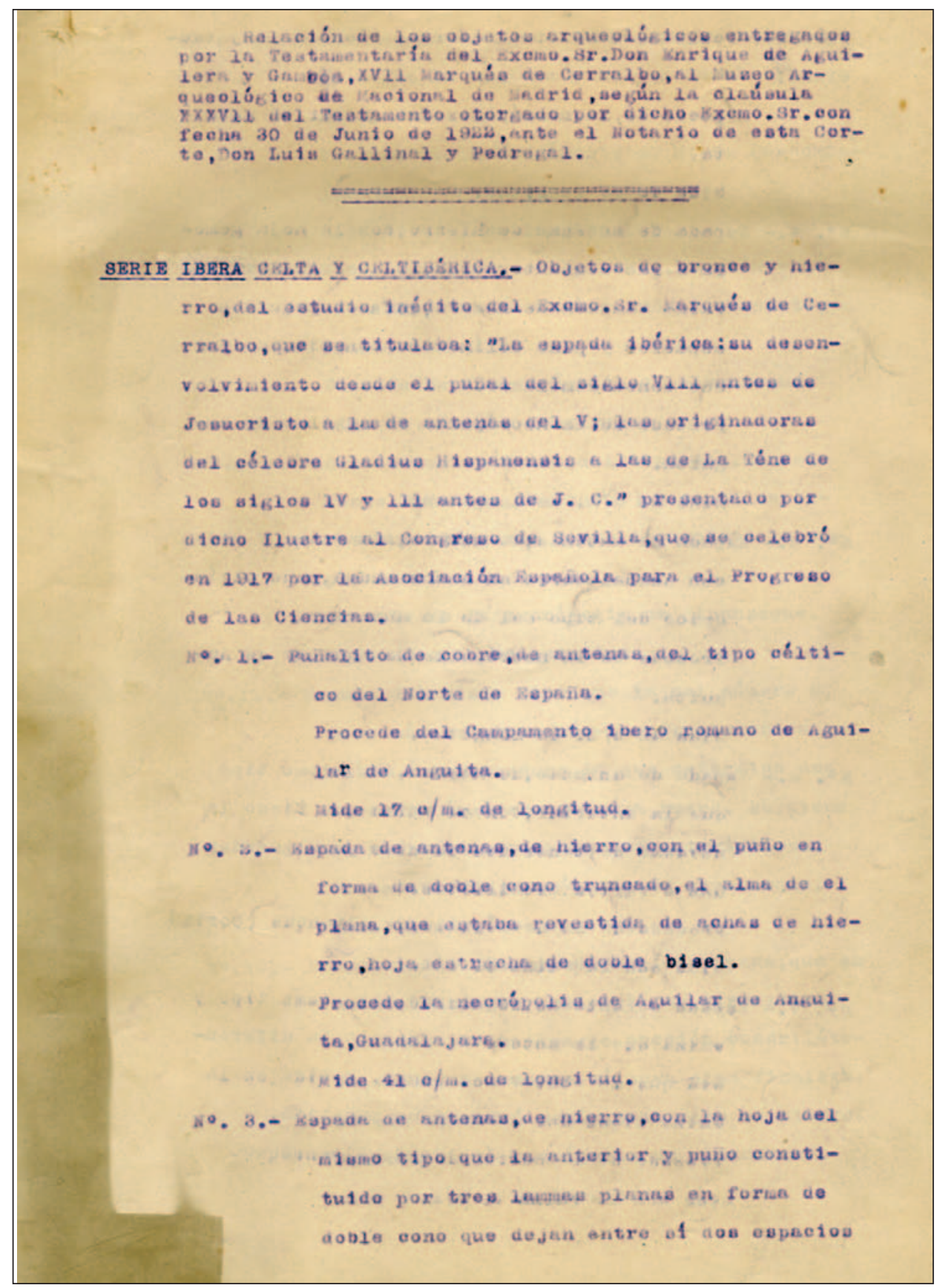

Figura 12. Primera página del Inventario realizado por Juan Cabré de los materiales procedentes de las excavaciones del marqués de Cerralbo. Legado familia Cabré, UAM (nº inv. 02047/1 ).

mación acerca de problemas históricas dentro de la arqueología española de la primera mitad del siglo XX, hoy imposible de soslayar si queremos reconstruir importantes lagunas de la citada investigación. Así, con el ejemplo concreto de la figura del XVII ${ }^{\circ}$ marqués de Cerralbo y su palacio de Santa María de Huerta, pensamos, que constituye un claro ejemplo de dicha afirmación.

A través de la fotografía hemos podido ensayar una reconstrucción de la arquitectura del palacio de Santa María de Huerta y que, a partir del 1908, fue convertido por el marqués de Cerralbo en el lugar desde el cual dirigió sus prospecciones y sus excavaciones arqueológicas. El marqués de Cerralbo, consciente de sus limitaciones formativas contó por un lado, con colaboradores de diversas profesiones desde fotógrafos, geólogos y arqueólogos, además de lugareños que le proporcionaban información sobre los hallazgos y por otro, no dudó en pedir opiniones de especialistas españoles y extranjeros para corroborar sus hipó- 
tesis y sus estudios. Toda aquella actitud quedo reflejada, sobre todo, en la correspondencia, además de las fotográficas y sus notas manuscritas. Con ello fomentó, no sólo las relaciones entre los investigadores españoles y extranjeros sino también promovió la difusión de sus estudios. Ello explica, pensamos, el que la Real Academia de la Historia le seleccionara como representante en el Congreso Internacional de Arqueología celebrado en Ginebra de 1911. Los años que dedicó a la Arqueología y a la protección del Patrimonio le aportaron una visión de la situación de los mismos, de ahí su participación en la elaboración de la primera Ley de Arqueología. Aquella pedagogía explica también la donación todos sus bienes al Estado procedente de casi un centenar de excavaciones al Museo Arqueológico Nacional y de los restos paleontológicas al Museo Antropológico Nacional.

De igual manera, pensamos que su relación con Juan Cabré es un tema poco tratado por la historiografía (Morán y Cabré, 1996; Jiménez y García-Soto, 2004) además, no siempre bien valorado o interpretado. Los documentos del Legado corroboran, de igual manera, la colaboración profesional e incondicional relación de amistad existente entre el marqués y Juan Cabré, cuestiones estas apuntadas por anteriores investigadores.

Fue una colaboración reciproca ya que, al tratarse de dos representantes de arqueología española de principios del siglo $\mathrm{XX}$, formaron parte de la transición que, dicha ciencia, experimento desde el coleccionismo y la erudición hasta una arqueología ya científica apoyada en instituciones universitarias y museológicas. De algunas de ellas fueron, incluso, sus propios impulsores y creadores, llegando a formar parte de los mismos. Ello, entre otras cuestiones, posibilitaron estudios y descubrimientos cruciales para la definición de, hasta entonces, desconocidos horizontes culturales de la Protohistoria peninsular caso, por ejemplo, del Arte rupestre levantino, las necrópolis de la II Edad de Hierro... por no citar sus aportaciones en la conservación del propio Patrimonio y su labor museológica.

Basta recordar cómo el marqués llegó a financiar sus excavaciones, hecho éste a tener en cuenta dado que, hasta 1911 todavía no estuvieron regularizadas por Ley. Él proporcionó los medios necesarios, almacenes y salas del estudio dentro del mismo palacio, además de los contactos que, tanto por su posición social como por su numerosos viajes por España y por el extranjero, le fueron accesibles. Todo ello configuró un panorama idóneo para aquel joven arqueólogo -Juan Cabréen su época formativa. De igual manera, el uso que él hizo de determinadas técnicas -como la fotográfica- las podemos considerar hoy pioneras al pasar de un uso meramente testimonial a utilizarla como documento del propio proceso de la investigación como bien reflejan sus excavaciones de campo.

Por todo hasta aquí expuesto, pensamos, que el estudio de legados documentales en general y, en concreto, el de la familia Cabré, permite, tanto ahondar en el conocimiento de la ciencia arqueológica de la primera mitad del siglo XX como ratificar o corregir tópicos he, equivocadas ideas que, como, en todo ciencia, están presentes en la historia de la arqueología española. El ejemplo que aquí hemos traído -el marqués de Cerralbo y su palacio de Santa María de Huertano es sino un modesto ejemplo de lo que en esta línea de investigación se puede hacer y en que grado de detalles se puede llegar en el conocimiento de la arqueología española. Los 15.850 documentos que hoy componen el Legado documental de Juan y María Encarnación Cabré no son pues, sino una puerta abierta a todo un mundo de posibilidades de investigación y de conocimiento científico, tan sólo a la espera de los investigadores den el paso.

\section{Bibliografía:}

ABAD, C. M. (1922): "El Museo Prehistórico del Marqués de Cerralbo". Razón y Fe 253, 51-62.

AGUILERA Y GAMBOA, E. (1916): "Las Necrópolis Ibéricas". Asociación Española para el Progreso de las Ciencias 2. Madrid.

AGUILERA Y GAMBOA, E. Marqués de Cerralbo (1913): "Les fouillesd'Aguilard'Anguita. Nécropole celtibérique. Stèle à gravure". Revue des Estudes Anciennes XV (4), 437-439.

ALMAGRO BASCH, M. (1942): "La necrópolis céltica de Griegos". Archivo Español de Arqueología 15 (47), 104-113.

ALONSO PEREIRA, J.R. (2005): Introducción a la Historia de la arquitectura. De los orígenes al siglo XXI. Estudios Universitarios de Arquitectura 8. Editorial Reverté S.A. Barcelona. 
ALVAR EZQUERRA, J. (2007): "El marqués de Cerralbo, la arqueología y el coleccionismo". J. Beltrán Fortes, B. Cacciotti y B. Palma Venetucci (eds.) Arqueología, coleccionismo y antigüedad: España e Italia en el siglo XIX, 23-36. Secretaría de Publicaciones de la Universidad de Sevilla. Sevilla.

AYARZAGÜENA SANZ, M. y MORA RODRÍGUEZ, G. (coords.), (2004): Pioneros de la arqueología en España. Del siglo XVI a 1912. Zona Arqueológica 3. Museo Arqueológico Regional. Madrid.

BAQUEDANO BELTRÁN, I. (1993): "Pioneros. Encarnación Cabré Herreros. La primera mujer en la arqueología española”. Revista de Arqueología 146, 46-51.

BAQUEDANO BELTRÁN, I. (2008): "Doña Encarnación Cabré. Sus trabajos arqueológicos en Guadalajara y en la colección Cerralbo". E. García-Soto, M.Á. García y J.P. Martínez (eds.) Actas del Segundo Simposio de arqueología de Guadalajara (Molina de Aragón 20-22 de abril de 2006), 489-516. Madrid.

BARRIL VICENTE, M. (2004): “Enrique de Aguilera y Gamboa, XVII marqués de Cerralbo”. En M. Ayarzagüena Sanz y G. Mora Rodríguez (coords.) Pioneros de la arqueología en España. Del siglo XVI a 1912. Zona Arqueológica 3, 187-196. Museo Arqueológico Regional. Madrid.

BLÁNQUEZ PÉREZ, J. y GONZÁLEZ REYERO, S. (2004): "D. Juan Cabré Aguiló. Comentarios oportunos a una biografía inacabada". J. Blánquez Pérez y B. Rodríguez Nuere (eds.) El arqueólogo Juan Cabré (1882-1947). La fotografía como técnica documental, 19-41. Universidad Autónoma de Madrid, Instituto de Patrimonio Histórico Español y Museo San Isidro. Madrid.

BLÁNQUEZ PÉREZ, J. y RODRÍGUEZ NUERE, B. (2004): El arqueólogo Juan Cabré (1882-1947). La fotografía como técnica documental. Universidad Autónoma de Madrid, Instituto del Patrimonio Histórico Español y Museo de San Isidro. Madrid.

BLÁNQUEZ PÉREZ, J. y ROLDÁN GÓMEZ, L. (eds.), (1999a): La cultura ibérica a través de la fotografía de principios de siglo. Vol.I. Un homenaje a la memoria. Universidad Autónoma de Madrid, Diputación de Albacete y Caja Madrid. Madrid.
BLÁNQUEZ PÉREZ, J. y ROLDÁN GÓMEZ, L. (eds.), (1999b): La cultura ibérica a través de la fotografía de principios de siglo. Vol.II. Las colecciones madrileñas. Universidad Autónoma de Madrid, Comunidad de Madrid, Real Academia de la Historia y Caja Madrid. Madrid.

BLÁNQUEZ PÉREZ, J. y ROLDÁN GÓMEZ, L. (eds.), (2000): La cultura ibérica a través de la fotografía de principios de siglo. Vol.III. El litoral mediterráneo. Caja de Ahorros del Mediterráneo y Universidad Autónoma de Madrid. Madrid.

BLÁNQUEZ PÉREZ, J., RORLDÁN GÓMEZ, L. y GÓNZALEZ REYERO, S. (coords.), (2008): Álbum. Investigaciones Arqueológicas en los Montes de Sn Antonio. Tosal redó, Humbries, Piuró y Mas de Magdalenes. Términos de Calaceite, Cretas (Teruel). Edición facsímil del manuscrito original. Universidad Autónoma de Madrid. Madrid.

BLASCO BOSQUED, C., BAENA PREYSLER, J., y LIESAU VON LETTOW-VORBECK, C. (1998): La prehistoria madrileña en el Gabinete de Antigüedades de la Real Academia de la Historia. Los yacimientos Cuesta de la Reina (Ciempozuelos) y Valdocarros (Arganda del Rey). Patrimonio Arqueológico del Bajo Jarrama 3. Universidad Autónoma de Madrid. Madrid.

CABRÉ AGUILÓ, J. (1915): “Arte rupestre en España (regiones septentrionales y orientales)". Comisión de Investigaciones Paleontológicas y Prehistóricas. Memoria $n^{o} 1$. Junta para Ampliación de Estudios e Investigaciones Científicas, Instituto Nacional de Ciencias FísicoNaturales y Museo Nacional de Ciencias Naturales. Madrid.

CABRÉ AGUILÓ, J. (1917): “Apéndice I. Casas-palacios señoriales". Catálogo Monumental de la Provincia de Soria. Tomo V. Arquitectura militar de la Edad media, 6567.http://biblioteca.cchs.csic.es/digitalizacion_tnt /index_interior_soria.html (Consultado: 22.06.2013).

CABrÉ Aguiló, J. (1922a): "El Marqués de Cerralbo. I.- Sus donaciones científicas. Su biografía". Ibérica: El progreso de las ciencias y de sus aplicaciones 451, 285-287.

CABRÉ Aguiló, J. (1922b): "El Marqués de Cerralbo. II Sus descubrimientos arqueológicos". Ibérica. El progreso de las ciencias y de sus aplicaciones 453, 314-317. 
CABRÉ AGUILÓ, J. (1942): "El rito céltico de incineración con estelas alineadas". Archivo Español de Arqueología 15, 339-344.

CABRÉ AGUILÓ, J. (1944): Corpus Vasorum Hispanorum. La cerámica de Azaila: museo arqueológico de Madrid, Barcelona y Zaragoza. Consejo Superior de Investigaciones Científicas e Instituto de Arte y Arqueología "Diego de Velázquez". Madrid.

CABRÉ AGUILÓ, J., MOLINERO PÉREZ, A. y CABRÉ, Ma . E. (1932): "La necrópolis de La Osera". Actas y Memorias de la Sociedad Española de Antropología, Etnografía y Prehistoria XI (1), 21-57.

CABRÉ HERREROS, E. y MORÁN CABRÉ, J. (1993): “Juan Cabré y la restauración”. Pátina 6. Homenaje a Raúl Amitrano, 114-120.

CABRÉ HERREROS, Mª .E. y MORÁN CABRÉ, J.A. (1984): “Cabré y arqueología céltica meseteña de Hierro II”. J. Cabré Juan Cabré Aguiló (18821982). Encuentro de Homenaje. Publicaciones de la "Institución Fernando el Católico", 65-78. Excma. Diputación Provincial de Zaragoza. Zaragoza.

CERDEÑO, Ma.L. y GARCÍA HUERTA R. (2004): "Las necrópolis celtibéricas y la obra de Juan Cabré”. J. Blánquez Pérez y B. Rodríguez Nuere (eds.) El arqueólogo Juan Cabré (1882-1947). La fotografía como técnica documental, 235-249. Dirección General de Cultura, Consejería de Educación y Cultura y Comunidad Autónoma de la Región de Murcia. Madrid.

CERDEÑO, M M $^{\mathrm{a}}$ L., MARCOS, F. y SAGARDOY, T. (2002): "Campos de Urnas en la Meseta Oriental: nuevos datos sobre un viejo tema". Trabajos de Prehistoria 59 (2), 135-147.

CERRALBO MARQUÉS DE (1900): “Conservación de monumentos". Del hogar castellano: estudios histórico y arqueológico vol. 103, 1-5. Biblioteca Patria. Madrid.

CERRALBO MARQUÉS DE, Enrique de Aguilera y Gamboa (1908): El Arzobispo D. Rodrigo Ximénez de Rada y el monasterio de Santa María de Huerta. Sucesores de Rivadeneyra. Madrid.

CERRALBO MARQUÉS DE (1912a): "Nécropoles ibériques". Congrés International d'Antropologie et d'Archéologie préhistoriques. Compte Rendu de la XIV ${ }^{m e}$ sesión Genève, 1912, 593-627.
CERRRALBO MARQUÉS DE (1912b): “Torralba, la plus ancienne station humaine de l'Europe". Congrés International d'Antropologie et d'Archéologie préhistoriques. Compte Rendu de la XIV ${ }^{m e}$ sesión Genève, 1912, 277-290.

CUADRADO DÍAZ, E. (1968): Excavaciones en la necrópolis celtibérica de Riba de Saelices (Guadalajara). Servicio Nacional de Excavaciones Arqueológicas 60. Ministerio de Educación Nacional, Dirección General de Bellas Artes. Madrid.

FARIELLO, F. (2004): La arquitectura de los Jardines. De la Antigüedad al siglo XX. Estudios Universitarios de Arquitectura 3. Editorial Reverté S.A. Barcelona.

Gaceta de Madrid (08 de julio de 1911): Ministerio de Instrucción Pública y Bellas Artes: Ley disponiendo se entiendan por excavaciones, (i los efectos de esta Ley, las remociones deliberadas y metódicas de terrenos, respecto á los cuales existan indicios de yacimientos arqueológicos, ya sean restos de construcciones ó ya antigüedades) Año CCL, T. III, $n^{\circ} 189,95-96$.

GARCÍA LOPÉZ, J.C. (1891): Santa María de Huerta (Soria): historia y descripción. Imp. M. Minuesa de los Ríos. Madrid.

GONZÁLEZ REYERO, S. (2006): La fotografía en la arqueología española (1860-1960). 100 años de discurso arqueológico a través de la imagen. Antiguaria Hispanica 15. Real Academia de la Historia y Universidad Autónoma de Madrid. Madrid.

JIMÉNEZ SANZ, C. (2002): "Los primeros descubrimientos arqueológicos del Marqués de Cerralbo noventa años después". E. García-Soto Mateos y M.Á. García Valero (eds.) Actas del Primer Simposio de arqueología de Guadalajara. Homenaje a Encarnación Cabré Herreros (Sigüenza 4-7 de octubre de 2000), 125-136. Madrid.

JIMÉNEZ SANZ, C. y GARCÍA-SOTO MATEOS, E. (2004): "Juan Cabré, Enrique de Aguilera y el Museo Cerralbo: apuntes sobre una relación científica y humana intemporal". J. Blánquez y B. Rodríguez (eds.) El arqueólogo Juan Cabré (1882-1947). La fotografía como técnica documental, 89-103. Universidad Autónoma de Madrid, Instituto del Patrimonio Histórico Español y Museo de San Isidro. Madrid. 
JIMÉNEZ SANZ, C. y GARCÍA-SOTO MATEOS, E. (2008): "El inventario de la colección Cerralbo elaborado por Juan Cabré Aguiló, un documento excepcional”. E. García-Soto Mateos, M.Á. García y J.P. Martínez (eds.) Actas del Segundo Simposio de Arqueología de Guadalajara (Molina de Aragón, 20-22 de abril de 2006), 517539. Madrid.

KASABAL (29 de julio de 1891): "El Rosario. A la señora marquesa de Cerralbo". El Heraldo de Madrid. Diario Independiente, Año II, $\mathrm{n}^{\circ} 271$, s/n.

MASFERRER， N. (5.08.1916): “Turismo \& Excursionismo. Corriendo por España por Soria y Guadalajara. De Santa María a Torija”. Stadium $167,519-529$.

MORÁN CABRÉ, J. y CABRÉ HERREROS, E. (1996): "Marqués de Cerralbo y Juan Cabré". Boletín de la Asociación de Amigos de la Arqueología 36, 23-35.

MUÑOZ JIMÉNEZ, J.M. (1999): “Historia del arte en la provincia de Guadalajara en torno al desastre del 98 ". Wad-al- Hayara: Revista de estudios de Guadalajara 26, 219-238.

NAVASCUÉS BENLLOCH, P de, CONDE DE BEROLDINGEN GEYR, C.; JIMÉNEZ SANZ, C. (1996): El marqués de Cerralbo. Ministerio de Cultura. Madrid.

NAVASCUÉS, P. de y CONDE DE BEROLDINGEN, C. (1998): El legado de un mecenas. Pintura española del Museo Marqués de Cerralbo. Ministerio de Educación y Cultura. Madrid.
RECIO MARTÍN, R.C., y CASAS DESANTES, C. (auts. texts.), (2012): Miradas. Páginas de la Historia. Una obra inédita. Junta Coordinadora de Publicaciones Oficiales del Ministerio de la Presidencia y Museo Cerralbo. Madrid.

SANTONJA ALONSO, M. y PÉREZ-GONZÁLEZ, A. (2004): "Las investigaciones del marqués de Cerralbo en los yacimientos pleistocenos de Torralba y Ambrona”. J. Blánquez Pérez y B. Rodríguez Nuere (eds.) El arqueólogo Juan Cabré (1882-1947). La fotografía como técnica documental, 149-165. Universidad Autónoma de Madrid, Instituto de Patrimonio Histórico Español y Museo San Isidro. Madrid.

VAQUERO ARGÜELLES, L. (coord.), (2002): Álbum. La colección de fotografía del Marqués de Cerralbo. Ministerio de Educación, Cultura y Deporte. Madrid.

VAQUERO ARGÜELLES, L., GRANADOS ORTEGA, Ma.A., RECIO MARTIN, R.C., y CASAS DESANTES, C. (2010): Guía del Museo Cerralbo. Ministerio de Cultura. Madrid.

WFYLER, A. (10. 1923): "Residencias Señoriales. El Palacio del Marqués de Cerralbo, en Santa María de Huerta”. Elegancia Año I, no 10, 18-19. 



\section{Normas para la redacción de originales}

1. Los originales deberán estar mecanografiados en formato DIN A-4 con un máximo de 34-36 líneas de 75 caracteres por página. No se podrán aceptar originales con mayor densidad de caracteres por página.

2. Junto con el texto mecanografiado se incluirá una copia del mismo en soporte magnético en formato Wordperfect, Word, o RTF. Se evitará el uso de tabuladores y retornos manuales salvo en los puntos y aparte. En la etiqueta se indicará el título del trabajo, autor/es y formato. Se procurará que el texto venga libre de erratas para facilitar la corrección de pruebas al Consejo de Redacción, ya que no se remitirán pruebas de imprenta a los autores por razones de coste.

3. Los artículos deberán venir acompañados de un resumen en la propia lengua del trabajo y en otra lengua de difusión internacional (español, inglés, francés, italiano, alemán). Los resúmenes tendrán una extensión máxima de 15 líneas de 75 espacios cada una.

4. Los artículos vendrán acompañados por un máximo de seis palabras clave que describan una rápida localización en una búsqueda informatizada por temática, metodología, cronología y localización.

5. La extensión máxima de los trabajos será de 40 páginas de texto y hasta 15 ilustraciones (dibujos o fotografías) si ocupan el evilante de la caja de CUPAUAM (24,5 x 16,5 $\mathrm{cm}$.), o hasta 20 ilustraciones si son de menor tamaño.

6. Todas las ilustraciones vendrán numeradas correlativamente, independientemente de que se trate de fotografía, dibujos a línea, gráficos o tablas. Los dibujos incluirán esca- la gráfica y se procurará que se adapten en sus proporciones a la caja de CuPAUAM $(24,5 \times 16,5 \mathrm{~cm}$.) -caja completa, media caja horizontal, o cuarto de caja-. Para el grosor de las líneas y densidad de sombras de los dibujos se tendrán en cuenta los porcentajes de reducción necesarios.

No se pueden realizar reproducciones a color. Las tablas de valores o datos vendrán integradas en el procesador de texto, en página aparte, con márgenes adecuados y numeradas correlativamente con el resto de las figuras. No se emplearán los términos "Tabla", "Cuadro", "Mapa", etc. En el caso de que tal cosa no sea posible, vendrán impresas o escritas a máquina electrónica y sin erratas, para que puedan ser reproducidas como una figura.

7. Se acompañará una hoja aparte con los pies de las figuras. Si proceden de otras publicaciones se citará la fuente. Es responsabilidad de los autores asegurar la cesión del copyright de las ilustraciones en caso necesario.

8. En el encabezamiento del trabajo, bajo el título y antes que el resumen, se indicará el nombre del/los autor/es, así como el centro o centros en que trabajen. El remitente indicará en hoja aparte los mismos datos, junto con su dirección, teléfono y fecha de envío del trabajo.

9. Se podrá usar el sistema tradicional de citas o el americano, o uno mixto, a elección del autor.

9.1. En notas cortas (referencia a un trabajo), se pondrá el nombre de éste en caracteres normales -no en mayúsculas-, seguido del año de edición de la obra, 
página o páginas y figura o figuras, todo ello separado por comas. Estas citas figurarán en el texto, entre paréntesis, y no al final ni al pie de la página.

9.2. Las notas largas deberán ir al final del texto, con las referencias bibliográficas igual que en 9.1.

9.3. Al final del artículo se incluirá la lista de la bibliografía citada, ordenada alfabéticamente según el primer apellido de los autores. Si un autor tienes varias obras citadas, se ordenarán de más antigua a más reciente. Si hay varias obras de un autor en un mismo año, se distinguirán con las letras minúsculas ( $a, b, c$, etc.) que se incluirán también en las referencias de 9.1 y 9.2 .

9.4. Cuando se trate de un libro se citará por este orden: apellidos e inicial del nombre del autor, fecha de edición entre paréntesis, dos puntos, título de la obra y lugar de edición.

9.5. Cuando se trate de un artículo de revista: autor, año, título del artículo entre comillas, nombre de la revista en cursiva, tomo o número, y páginas.

9.6. En colaboraciones en libros colectivos: autor, año, título de la colaboración, título del libro (con el nombre del editor o coordinador en su caso, tomo y páginas, lugar de edición).

9.7. El nombre de los autores irá en letras mayúsculas en la Bibliografía final (no así en el cuerpo del texto, véase 9.1.). El título de los libros y de las revistas, subrayado o en cursiva; el de los artículos de revistas y colaboraciones, entre comillas.
9.8. Si se citan abreviadamente títulos de revistas o series, se emplearán las abreviaturas de CUPAUAM para revistas españolas, y algún sistema reconocido internacionalmente (L'Année Philogique, Archáologische Bibliographie, American Journal of Archaeology) para las extranjeras.

\section{Ejemplos de citas:}

9.1. (Abad Casal, 1991:185).

9.2. ...recientemente. Abad Casal (1991:185) indica que...

9.4. GARCÍA Y BELLIDO, A. (1949): Esculturas romanas de España y Portugal. Madrid.

9.5. ABAD CASAL, L. (1983): "Un conjunto de materiales de la Serreta de Alcoy". Lucentum 2, 173-197.

9.6. BELTRÁN LLORIS, M. (1987): "La España celtibérica: la segunda Edad del Hierro en el Valle del Ebro". Historia General de España y América, 1.2, 255-293. Madrid.

10. Los artículos serán revisados por al menos dos evaluadores del Consejo Consultivo y del Consejo Asesor Externo.

11. El Consejo de Redacción se reserva el derecho de devolver los originales que no se correspondan con la línea de la Revista, o que no cumplan estas normas de redacción. El Consejo asesor, a través de su sistema de evaluación, podrá asimismo sugerir las modificaciones que estime oportunas a los originales aceptados. 

